\title{
Gender and Aggressive Behavior: A Meta-Analytic Review of the Social Psychological Literature
}

\author{
Alice H. Eagly and Valerie J. Steffen \\ Purdue University
}

\begin{abstract}
In our meta-analytic review of sex differences in aggressive behavior reported in the social psychological literature we found that although men were somewhat more aggressive than women on the average, sex differences were inconsistent across studies. The magnitude of the sex differences was significantly related to various attributes of the studies. In particular, the tendency for men to aggress more than women was more pronounced for aggression that produces pain or physical injury than for aggression that produces psychological or social harm. In addition, sex differences in aggressive behavior were larger to the extent that women, more than men, perceived that enacting a behavior would produce harm to the target, guilt and anxiety in oneself, as well as danger to oneself. Our interpretation of these results emphasizes that aggression sex differences are a function of perceived consequences of aggression that are learned as aspects of gender roles and other social roles.
\end{abstract}

The conditions under which women and men differ in aggressiveness are not well understood. Psychologists have defined aggression as behavior intended to inflict harm or injury (e.g., Baron, 1977; Berkowitz, 1964), and for many years have studied such behavior in situations especially designed to elicit it. Although the sex differences found in this literature have been reviewed previously, most reviewers (e.g., Hyde, 1984, 1986; Maccoby \& Jacklin, 1974, 1980) have focused primarily on children's aggressive behavior. Yet the tendency for males to be more aggressive than females is larger among children than adults in both psychological (Hyde, 1984) and ethnographic (Rohner, 1976) research. Furthermore, the methods used to study aggression are quite different in the child and adult literatures. Therefore, reviews containing a substantial proportion of child studies not only provide larger estimates of sex differences in aggression than are valid for adults but also may emphasize determinants of aggression that are valid primarily for children.

Like Frodi, Macaulay, and Thome's (1977) review, ours is limited to sex differences in adult aggressive behavior. Yet, in contrast to Frodi et al.'s narrative mode of research integration, we used meta-analytic methods (Glass, McGaw, \& Smith, 1981 ; Rosenthal, 1984). By using such methods, we were able to (a) estimate the overall magnitude of sex differences in aggression, (b) examine whether these sex differences are consistent across

This research was supported by National Science Foundation Grant BNS-8216742.

We thank Larry Hedges for guidance concerning statistical analysis; Robert V. Eagly for help with computer programming; and Miriam Lerner, Kim McGuigan, Ellen Drury, and Katherine M. Markee for help in locating studies. We also thank Shelly Chaiken, Kay Deaux, Judith Hall, and Janet Hyde for their comments on an earlier draft of the article.

Valerie Steffen is now at Kent State University.

Correspondence concerning this article should be addressed to Alice H. Eagly, Department of Psychological Sciences, Purdue University, West Lafayette, Indiana 47907. studies, and (c) account for variation in the magnitude and direction of the sex differences across studies.

We limited our sample to studies with behavioral measures and thus omitted studies that assessed aggressiveness by means of projective and other self-report measures. Although some other reviewers (e.g., Hyde, 1984; Maccoby \& Jacklin, 1974, 1980) have included projective and self-report measures, the relation between responding aggressively on such measures and behaving aggressively is not necessarily strong. The decision to include only behavioral measures ensures comparability with most other meta-analyses of sex differences in social behavior (e.g., Eagly \& Carli, 1981; Eagly \& Crowley, 1986; Hall, 1984; Hall \& Halberstadt, 1986) and focuses this meta-analysis on the social psychological literature on aggression, in which behavioral measures have been used.

Like the prior reviewers, we excluded from consideration numerous applied literatures on aggressive behavior-for example, research on violent crime. Although research in such areas adds to our understanding of gender-related aspects of aggression, such behaviors reflect many factors in addition to the tendency to aggress-for example, crime reflects access to opportunities for participating in criminal activity.

As a consequence of these several criteria for excluding studies, our review is limited to studies in which adult subjects were exposed to a standardized situation designed to elicit aggressive behavior. Most such studies were conducted in experimental laboratories, although a substantial minority were conducted in field settings. In the laboratory-experimental tradition, there has been heavy reliance on a "teacher-learner" paradigm (e.g., Buss, 1963) in which college student subjects take the role of a teacher who must deliver electric shocks or other aversive stimuli to punish a learner for apparent errors. Within the fieldexperimental tradition, aggression has been elicited by exposing people to a mildly frustrating event such as someone cutting into line in front of them (e.g., Harris, 1974) or a driver not moving when a traffic light turns green (e.g., Doob \& Gross, 1968). None of the studies in our sample examined aggression 
in close personal relationships or organizational contexts. Rather, aggression occurred during relatively brief encounters between strangers.

\section{Social-Role Interpretation of Sex Differences}

Our search for predictors of sex differences in aggression was guided by a social-role or structural approach (e.g., Eagly, 1983; Eagly \& Crowley, 1986). Like other social behaviors, aggression can be viewed as role behavior and therefore as regulated by the social norms that apply to people based on the roles they occupy (see also Lubek, 1979). To account for sex differences in aggression from this perspective, we must understand the ways in which aggression is sustained or inhibited by the social roles occupied mainly or exclusively by persons of each sex. Gender roles are one important class of social roles in this analysis. Yet other roles, if they are occupied primarily by one sex (e.g., military roles, homemaker role), can also underlie sex differences in aggressive behavior. More generally, this social-role approach is compatible with a contextualist perspective (McGuire, 1983) concerning gender, by which sex differences in a given behavior such as aggression are expected to vary across studies because they are contingent on the particular social norms salient in a setting.

By providing a single, integrative theoretical perspective, this social-role framework serves as a macrotheory for understanding sex differences in psychological processes that may underlie aggression. Maccoby and Jacklin (1974) and Frodi et al. (1977) discussed many such underlying processes, and we shall as well. In our approach, hypotheses about sex differences in processes that underlie aggression derive from an analysis of the social roles commonly occupied by women and men.

\section{Gender Roles and Aggression}

We first explore gender roles as an explanation of sex differences in aggression. These roles consist of the norms that apply to individuals because of their socially identified gender.

The male gender role. The male gender role includes norms encouraging many forms of aggression. Psychologists and popular writers who have analyzed the male gender role have claimed that men are expected to be tough, violent, and aggressive. To validate this idea, some writers (e.g., Fasteau, 1974) have pointed to the prevalence of aggressiveness among male heroes in literature and the popular culture. Psychologists' studies of stereotypes about men have documented more explicitly that people expect men to be aggressive (see the review by Cicone \& Ruble, 1978). Similarly, research on gender stereotypes has shown that men are rated as more aggressive than women and as more extreme on related qualities such as assertiveness and competitiveness (e.g., Broverman, Vogel, Broverman, Clarkson, \& Rosenkrantz, 1972; Ruble, 1983; Spence \& Helmreich, 1978). Gender stereotype research has also established that such qualities are considered more desirable in men than women.

Numerous public opinion surveys document that men are more approving of aggression than are women. Survey findings, recently reviewed by Smith (1984), have shown repeatedly that men have more favorable attitudes than women toward aggres- sive and violent behavior in realms as diverse as international relations and war, social control and law enforcement, interpersonal relations, and the portrayal of violence on television.

Despite evidence suggesting that aggressiveness is a component of the male gender role, this role may also include norms that foster some behaviors incompatible with aggression. Specifically, the traditional male role encompasses norms of chivalry as well as aggressiveness (see Eagly \& Crowley, 1986). The ideology of chivalry stipulates that men should protect the weak and defenseless and be courteous and protective to subordinates. Rules of chivalry may temper male aggressiveness, at least toward subordinates, within some social contexts. Furthermore, as Pleck (1981) has argued, less traditional forms of the male gender role may de-emphasize aggressiveness and support communal qualities such as sensitivity to other people and emotional expressiveness.

The female gender role. The traditional female gender role places little emphasis on aggressiveness. Also, the primacy that this role gives to caring and other communal qualities (see Eagly \& Crowley, 1986) may favor behaviors incompatible with aggressiveness toward other people. In addition, the female gender role emphasizes avoiding physical harm to oneself. In particular, rules of caution and avoidance of strangers, intended in part to lessen the possibility that girls and women become victims of sexual assault (e.g., see U.S. Department of Justice, 1979), may lead women to be less aggressive than men in situations in which physical retaliation is likely.

In contrast, less traditional forms of the female gender role include an emphasis on assertiveness, a quality advocated by feminists. Assertiveness, although popularly regarded as synonymous with aggressiveness, has often been distinguished from it by proponents of assertiveness training (e.g., Bloom, Coburn, \& Pearlman, 1975; Fensterheim \& Baer, 1975). Advocates of assertiveness have emphasized the lack of harmful intent underlying assertive behaviors versus the presence of such intent underlying aggressive behaviors. Nevertheless, the support for women's assertiveness in recent years suggests that the female gender role, like the male gender role, conveys complex messages about aggression and related behaviors.

\section{Other Social Roles and Aggression}

Some aggressive behaviors may be more common in one sex because they are aspects, not of gender roles, but of other social roles occupied primarily by that sex. Particularly important are military and athletic roles, because a substantial proportion of all males occupy such roles sometime during their lives and therefore receive important socialization in aggressiveness in these contexts.

As Arkin and Dobrofsky (1978) argued, military roles foster a number of traditionally masculine values. Aggressiveness is central among these values. Yet military aggressiveness is supposed to be expressed only within defined limits and only toward military enemies. Nevertheless, military indoctrination may transmit an ideology that legitimizes a wide range of aggressive behavior.

Participation in competitive sports may also promote aggressive behavior as well as an ideology that supports aggressiveness (Stein \& Hoffman, 1978). Because men are more likely than 
women to have gained experience in competitive sports, the behavior and the values fostered in athletic roles affect more men than women. Like military roles, athletic roles require controlled aggressiveness, directed in this instance primarily toward opposing players and teams.

Most occupations pursued disproportionately by men lack such clear-cut implications for aggressiveness. Yet managerial roles in business and industry may incorporate an element of aggressiveness. Although aggressive behavior typical of these roles is primarily directed externally toward rival companies, a pattern of competitive (if not openly aggressive) behavior toward fellow employees is sometimes held to typify American managers (e.g., McClelland, 1961; Whyte, 1956).

Most occupations pursued disproportionately by women discourage aggressive behavior and emphasize some form of giving help to others. For example, over half of all women in the paid labor force are in clerical and service occupations and women with professional positions are predominantly teachers and nurses (U.S. Department of Labor, 1980). In addition, the homemaker role emphasizes care-giving and other forms of personal service, although it does foster aggressive behavior in defense of one's children. Indeed, this aggressive behavior is in the service of others.

Finally, one aspect of social roles that has general relevance to sex differences in aggression is the distribution of the sexes into higher and lower status roles (Eagly, 1983). Men are likely to have higher status than women in organizations of all kinds and in the family. Although high status does not necessarily imply that an individual should behave aggressively, subordinate status enjoins many types of aggression, particularly aggression directed toward people of higher status.

\section{Predictions From Social-Role Analysis}

Overall sex-of-subject difference. The several aspects of our social-role analysis all suggest that the overall aggression sex difference would tend to be in the male direction. Indeed, past reviews have found such an overall difference. Yet as we have argued, the female and male gender roles differ in emphasis but both roles incorporate norms that encourage and norms that discourage aggressiveness. Consequently, sex differences in adult aggressive behavior may not be any larger than those established for other social behaviors (see Hall, 1984). Furthermore, the magnitude of sex differences in aggression should vary considerably across studies because of the complexities we have noted in the ways social roles regulate aggression.

Effect of contextual variables on sex differences in aggression. Our social-role framework directed attention to certain contextual features of studies of aggression. Most importantly, we tested the hypothesis that sex differences are larger for aggression causing pain or physical injury in the target person than for aggression causing psychological or social harm. ${ }^{1}$ Our interest in this hypothesis stems from its consistency with aspects of our social-role analysis. For example, our claim that the female role includes norms that discourage placing oneself in physical jeopardy suggests that women would avoid physical aggression because of its greater likelihood of provoking physical retaliation. Also supporting the prediction of larger sex differences for physical versus psychological aggression is the argument that military and athletic roles emphasize primarily physical aggression.

Frodi et al. (1977) suggested that sex differences in aggression were little affected by whether aggression has physical or psychological effects. Yet Hyde (1986) found that the tendency for men (and boys) to be more aggressive than women (and girls) was nonsignificantly larger for physical than psychological aggression. Because Hyde's sample included few studies assessing psychological aggression, we sought a larger sample to test the hypothesis of larger sex differences for physical than psychological aggression.

On an exploratory basis, our meta-analysis also examined several other situational variables as correlates of aggression sex differences. One such variable is whether subjects exercised freedom of choice about aggressing or were required to deliver an aggressive behavior (and therefore merely chose the intensity of the act). The amount of provocation or frustration that subjects faced was also examined. Strong external pressures in terms of either reduced freedom of choice or extreme provocation might outweigh gender-related normative factors and therefore lessen any sex differences.

Studies were also classified according to whether the aggressor was likely to have been under surveillance by other people. An audience of onlookers might often increase the magnitude of sex differences in aggression, because it would make gender role obligations salient (Richardson, Bernstein, \& Taylor, 1979). In contrast, the possibility that surveillance by onlookers might reduce the likelihood of retaliation by the target suggests that the sex difference may be lessened by an audience, if it is true that women often avoid aggression that may lead to retaliation. Furthermore, the absence of surveillance by the target could also reduce the likelihood of retaliation and thereby lessen the sex difference, because a target cannot retaliate against an unknown or absent aggressor. The complexity of these considerations underscores the exploratory status of the surveillance variable in our meta-analysis.

Studies were also classified according to their laboratory or field setting, even though the variability of the field paradigms makes it difficult to predict the impact of this situational variable. Finally, the number of behaviors aggregated in the aggression measure was recorded for each study. For example, a "teacher-learner" experiment (e.g., Buss, 1963) in which the teacher is supposed to shock the learner for each of 36 mistakes provides an aggression measure aggregated over 36 behaviors. To the extent that measures were based on multiple observa-

\footnotetext{
${ }^{1}$ The distinction between physical and psychological aggression has appeared in more than one variant in the aggression literature. Some investigators (e.g., Buss, 1961) have distinguished between these two types of aggression based on the overtly physical versus vocal nature of the aggressor's act. Following Frodi, Macauley, and Thome (1977), we prefer to focus on the type of harm to the target. Yet Frodi and her collaborators labeled aggression causing psychological or social harm (e.g., hurt feelings, lowered self-esteem, damage to one's reputation) as verbal aggression, not psychological aggression. We prefer the term $p s y$ chological aggression because it refers to the type of harm and, unlike verbal aggression, it encompasses the nonverbal aggressive behaviors assessed in some of the studies we reviewed. In the research on aggression, experimental situations typically allowed either psychological or physical aggression-not both.
} 
tions over occasions or situations, they should yield more reliable estimates of sex differences. The logic underlying this relation between the number of observations and the reliability of the sex difference is analogous to the relation between the number of items in a test and the reliability of the total test (e.g., Ghiselli, 1964). Reliable indicators of aggression should be more strongly related to subjects' sex and should also yield more stable estimates of sex differences in aggression.

Effect of psychological processes on sex differences in aggression. To illuminate the psychological processes that may mediate the impact that social roles have on behavior, we considered including both the skills and the beliefs that roles impart. An analysis of aggression from the standpoint of skills suggests that people are able to behave aggressively to the extent that they have acquired the relevant skills. As Eagly and Crowley (1986) argued, skills are often acquired primarily by one sex because people of this sex are more likely to occupy and anticipate occupying roles in which such skills are required. For example, skills relevant to physical aggression may be more common in men than women because these skills are imparted in both military and athletic roles. However, despite the probable importance of aggressive skills in natural settings, we did not assess sex differences in skills in this meta-analysis because the particular behaviors examined in aggression research required very little in the way of specialized skills (see the descriptions of behaviors given in Table 3), and none of the aggressive behaviors involved strenuous physical combat.

An analysis of aggression from the standpoint of beliefs suggests that people behave aggressively to the extent that their beliefs about the consequences of aggression legitimize aggression and that people behave unaggressively to the extent that their beliefs inhibit aggression. Emphasis on the perceived consequences of aggression follows from an expectancy value viewpoint (e.g., Feather, 1982; Fishbein \& Ajzen, 1975), by which attitude toward a behavior is a determinant of engaging in the behavior and is itself a function of the perceived consequences of the behavior. In particular, the male gender role's emphasis on aggression may decrease the perceived likelihood of the negative outcomes of (a) guilt and anxiety about causing people to suffer and (b) harm to others. In contrast, the female gender role's emphasis on caring and concern for others' welfare may increase the perceived likelihood of (a) guilt and anxiety about causing people to suffer and (b) harm to others. These differing reactions may stem from other social roles as well. For example, military and athletic roles may foster beliefs that support aggression, whereas caring roles such as homemaker and nurse foster reactions that inhibit aggression.

Research has repeatedly demonstrated that women report more guilt and anxiety about behaving aggressively than men do (see Frodi et al., 1977). This sex difference in guilt and anxiety may underlie a sex difference in aggression, if, as Frodi et al. argued, guilt and anxiety about aggression are negatively associated with the tendency to aggress. Therefore, in this meta-analysis, the magnitude of sex differences in aggression should be positively associated with the tendency for women (vs. men) to view an aggressive behavior as causing themselves more guilt and anxiety.

Beliefs about harming others are usually discussed in terms of empathy with the targets of aggression. Several scholars have argued that women (and girls) are generally more empathic or sympathetic than men (and boys) (e.g., N.D. Feshbach, 1982; Hoffman, 1977). Yet, in agreement with our social-role theory, Eisenberg and Lennon (1983) showed that this sex difference has been obtained primarily when demand characteristics or gender role obligations are salient. With respect to the specific hypothesis that women's greater empathy mediates sex differences in aggressiveness, Frodi et al. (1977) reported mixed empirical support. This mixed support may well be consistent with our role theory expectation that only some situations elicit more empathy in women than men, and in these situations men are more aggressive than women. Therefore, the magnitude of sex differences in aggression should be positively associated with the tendency for women (vs. men) to view an aggressive behavior as causing more harm to others.

Another likely sex difference in beliefs about the consequences of aggression is a tendency for women to believe that their aggressive behaviors pose dangers to themselves, for example, from retaliation by the target. As we have argued, the female gender role may include norms discouraging women from placing themselves in physical jeopardy. In contrast, in various male-dominated roles, especially in the military and in athletics, people may learn to disregard possible harm to themselves. As a consequence, the magnitude of sex differences in aggression would be correlated with the tendency of women to perceive their aggressive behaviors as more dangerous to themselves than men do. Consistent with this logic, a recent metaanalytic study (Eagly \& Crowley, 1986) showed that men were more helpful than women to the extent that women perceived their helping behaviors as more dangerous to themselves than men did.

Sex differences in beliefs about the negative consequences of aggression (guilt and anxiety, harm to others, and danger to oneself) are the most likely psychological mediators for the sex differences in aggressive behavior reported in the research we have reviewed. Yet these beliefs do not constitute a sufficient mediational theory of the impact of social roles on aggressive behavior. For example, we have not considered sex differences in the positive consequences that may be perceived to follow from aggression and may thus foster a desire to aggress (see Frost \& Averill, 1982). In addition, the contextual variables assessed in this meta-analysis are not assumed to exhaust the situational considerations inherent in our role analysis. Instead, we have included those theory-relevant situational and psychological factors that (a) vary across the studies in the aggression literature and (b) can be assessed from available research reports.

Sex-of-target effects. Our meta-analysis examined the effects of the sex of the target of aggression in those studies in which aggressor sex was crossed with target sex. In terms of our social-role analysis, overall sex-of-target effects are more difficult to predict than overall sex-of-subject effects. Although the inclusion of chivalry norms in the male gender role suggests that men may temper their aggressiveness toward women, these norms are often violated or are not relevant in various situations. Under such circumstances, women may be victimized more than men because of women's subordinate social status and lesser physical strength. Yet most of the situations examined in aggression research involved some type of explicit or implicit surveillance of subjects' behavior, which should often 
heighten the salience of norms that temper men's aggression toward women.

Women may also temper their aggression toward female targets to the extent that they perceive female targets as weaker and more vulnerable than male targets, especially if women are particularly empathic about victims' suffering. Yet, to the extent that women's subordinate social status and lesser physical strength vis-á-vis men inhibit their aggression toward men, we could argue that women would aggress more toward other women than toward men.

Given these considerations, predicting sex-of-target effects requires more knowledge than aggression studies have provided concerning these, and perhaps other, normative factors. Nevertheless, although overall sex-of-target effects should not be large in this meta-analysis, we expected that on the whole, subjects (especially men) aggress more against men than women in the settings used in the research literature. The expectation of more aggression against men than women is consistent with Frodi et al.'s (1977) generalization, which was based on a narrative review of a small number of studies.

In conclusion, the overall predictions for this meta-analysis are that (a) men are more aggressive than women and (b) men receive more aggression than women. Yet, our social-role analysis suggests that these sex differences should be quite variable across studies. As we have explained, features of social settings as well as people's beliefs about the consequences of aggressive acts should account for variability in the magnitude of the sex differences.

\section{Method}

\section{Sample of Studies}

A computer-based information search was conducted of the following data bases: PsycINFO (Psychological Abstracts), 1967-1982; Pre-Psyc, 1981-1983; ERIC, 1966-1983; Social SciSearch, 1967-1983; and Sociological Abstracts, 1963-1983. The end point for each search was the latest information available in the summer of 1983 . The key words used in the searches included the following terms: aggression, aggressiveness, aggressive behavior, antisocial behavior, hostility, hostile behavior, violence, and violent behavior. We also searched through (a) all bibliographies published in the journal Aggressive Behavior from 1974 (Vol. 1) through 1983 (Vol. 7); (b) the reference lists of numerous review articles, chapters, and books on aggression in general and on aggression sex differences; (c) the reference lists of the journal articles in our sample of aggression studies; and (d) volumes of the journals with the largest number of aggression studies.

The criteria for including studies in the sample were (a) the dependent variable was an aggressive behavior directed toward another person, (b) the reported results were sufficient to calculate a sex-of-subject effect size or to determine the statistical significance and/or direction of the sex difference, and (c) the subjects were female and male adults or adolescents (age 14 or older) from the United States or Canada who were not sampled from specialized populations (e.g., criminals, mental hospital patients, or particular occupational groups). Although the subjects in the majority of studies were college undergraduates, one study (Titley \& Viney, 1969) involved high school seniors. Field studies often sampled populations (e.g., car drivers) that include older adolescents and adults.

Studies were omitted if the process by which female and male subjects had been selected equalized their status on a personality variable that has been found to correlate with both sex and aggression. The sex difference in aggression could not be accurately estimated in studies with such a selection process. ${ }^{2}$ In addition, studies were excluded if they assessed aggressive behaviors that we judged may be largely manifestations of factors other than the tendency to aggress. This criterion excluded studies of crime and delinquency, vandalism, family violence, suicide and other self-aggression, sentencing in trials, role-played aggression, reward allocation, bargaining, and obedience. We also excluded studies of the effects of drugs on behavior and aggression toward animals.

The resulting sample (see the Appendix) of 63 studies yielded 81 sexof-subject reports. One study (Lando, Johnson-Payne, Gilbert, \& Deutsch, 1977) was treated as two because each of its two parts (a) assessed a different aggressive behavior, (b) used an independent sample of subjects, and (c) reported a separate sex-of-subject difference. Each study contributed one sex-of-subject report, with the exception of 12 studies that yielded two reports, 1 that yielded three reports, and 1 that yielded five reports. When several dependent measures in a study all were reported as having no significant sex-of-subject or sex-of-target difference (and no further information was provided), these measures were combined into a single report because of our uncertainties about the validity of some of the peripheral measures of aggression in several of the studies using many measures.

\section{Variables Coded From Each Study}

The following information was recorded for each report: (a) date of publication, (b) source of publication (journal, other source), (c) percentage of male authors, (d) sex of first author, and (e) sample size (female, male, and total). In addition, the following variables were coded from the information provided: (a) number of behaviors or responses aggregated in the aggression measure; (b) setting (laboratory; field); (c) type of aggression (physical, including shocking, delivering noxious noise, and hitting; psychological, including vocal, nonverbal, and written); (d) surveillance of aggressive act (private, i.e., not under anyone's immediate surveillance, e.g., questionnaire ratings; semiprivate, i.e., accessible to target and/or experimenter; public, i.e., accessible to additional onlookers); (e) freedom of choice to aggress (aggression required; free choice); (f) amount of provocation (minimal, i.e., an impediment to the subject's progress; greater than minimal, including insult, physical harm, violation of rights, assignment of an impossible task, and blockage of opportunity to win money); (g) sex of target of aggression (male; female; varied; same sex as subject). ${ }^{3}$ These variables were coded

\footnotetext{
${ }^{2}$ By this criterion, the following studies were removed from the sample: Carver (1974, 1975), Hoppe (1979), Knott and Drost (1970), Leventhal and Shemberg (1969), Leventhal, Schemberg, and Van Schoelandt (1968), Pentz (1980), Rothaus and Worchel (1964), and Shemberg, Leventhal, and Allman (1968).

${ }^{3}$ We did not code whether aggression was direct (i.e., the target of aggression was the person who instigated anger or provoked aggression) or indirect (i.e., the target was neither instigator nor provoker) because the exclusion of studies with self-report and projective measures removed most instances of indirect aggression. Although Frodi, Macauley, and Thome (1977) considered negative written evaluations of instigating or provoking persons to be indirect aggression (e.g., S. Feshbach, 1955), we considered them direct aggression because in most studies these evaluations were presumed to be available to supervisory personnel, and often to the instigator or provoker at some later point. Also, the extent to which aggression was justified was not coded because (a) most studies provided some justification for aggression, such as its value in teaching a learner; (b) justification usually did not vary with degree of aggression (e.g., magnitude and duration of shock delivered), which constituted the dependent variable in most studies; and (c) to the extent that high levels of aggression were justified, such justification usually followed from provocation of the subject, a variable included in the meta-analysis.
} 
by the authors, who agreed on $85 \%-100 \%$ of their judgments, depending on the variable. Disagreements were resolved by discussion. Preliminary analyses using more detailed categorization of types of aggression and types of provocation failed to yield improved prediction of effect sizes.

\section{Variables Derived From Questionnaire Respondents' Judgments of Aggressive Behaviors}

A questionnaire study was conducted to generate measures of the extent to which each aggressive behavior elicited sex differences in beliefs about the consequences of aggression and in the perceived likelihood of aggression. The likelihood measures were included to allow us to evaluate how well respondents' implicit theories of their own and others' behavior predicted the sex differences in aggression obtained in the research literature.

Respondents. ${ }^{4}$ The sample consisted of 97 female and 103 male undergraduates who received partial course credit for participating.

Procedure. Respondents participated in groups of about 25 , in sessions conducted by a female experimenter. Each respondent completed one of two versions of a questionnaire that took approximately $1 \mathrm{hr}$. Each version contained brief descriptions of half of the aggressive behaviors investigated in the studies used in the meta-analysis. For example, Buss's (1963) study was described as "Choosing at least moderately painful electric shocks to administer to an adult pupil sitting out of view; you are a subject in a psychological experiment in which you are to choose the level of electric shock to administer for mistakes on a task that you have been assigned to teach the person." Doob and Gross's (1968) study was described as "Honking at least once at a man driving a car stopped at a traffic light in front of you on a Sunday when there is not much traffic; this car did not start moving after the light turned green."

Respondents judged these behaviors in reaction to three questions assessing beliefs about aggression: (a) How harmful would this act be to the person it is directed toward? (b) How much anxiety or guilt would you feel if you enacted this behavior? (c) How much danger would you probably face if you enacted this behavior? Respondents also judged these behaviors in reaction to three likelihood questions: (a) How likely is it that you would enact this behavior? (b) How likely is it that the average woman would enact this behavior? (c) How likely is it that the average man would enact this behavior? These ratings were made on 15 point scales. The questionnaire was divided into six parts, each of which elicited respondents' judgments in relation to one of these six questions. The order of the first two parts was counterbalanced, as was the order of the last two. Within each part, the descriptions of the behaviors appeared in one of two random orders.

Analysis of ratings. For the first four of the six questions just listed, mean scores for each aggressive behavior were computed separately for female and male respondents. For each behavior, the female mean was subtracted from the male mean to yield a mean sex difference, which was standardized by dividing it by the pooled (within-sex) standard deviation. For the last two questions, the respondents' mean rating of the average woman for each behavior was subtracted from their mean rating of the average man to yield a mean stereotypic sex difference, which was standardized by dividing it by the standard deviation of the differences between the paired ratings.

\section{Computation and Analysis of Effect Sizes}

The effect size index used in the present study is $d$, the difference between the means of two groups, divided by the pooled (within-sex) standard deviation. For sex-of-subject effect sizes, this computation was based on (a) $t$ or $F$ for 35 reports, ${ }^{5}$ (b) means and standard deviations or error terms for 7 reports, and (c) the proportions of men and women who aggressed for 8 reports. For the proportions, the probit transformation recommended by Glass et al. (1981) was used to compute $d$. All effect-size calculations were performed independently by each of the authors, who then resolved any discrepancies.

The statistical significance and/or direction of the 81 reported sex-ofsubject differences was recorded, and an effect size (d) was calculated for the 50 behaviors for which sufficient information was provided. Whenever possible, these procedures were also carried out for the sexof-target differences as well as for the simple effects of (a) sex of subject for female and male targets and (b) sex of target for female and male subjects. If possible, the significance of the Sex of Subject $\times$ Sex of Target interaction was also recorded.

The effect sizes were corrected for the bias from $d$ 's overestimate of the population effect size, especially for small samples (Hedges, 1981). Then the study outcomes were combined by averaging the effect sizes. To determine whether the studies shared a common effect size, the homogeneity of each set of effect sizes was examined (Hedges, 1981). In addition, the normality of the distributions of effect sizes was assessed. Deviations from normality may be diagnostic of various problems discussed by Light and Pillemer (1984), such as the presence of outliers and the omission of smaller effect sizes due to publication bias. Yet if the effect sizes are not homogeneous, tests of normality should be interpreted with caution because they presume that the data are from a single population. Both categorical and continuous models were tested (Hedges, 1982a, 1982b; Hedges \& Olkin, 1985). In addition, counting methods were applied (Rasenthal, 1978, 1984).

\section{Results}

\section{Sex-of-Subject Differences}

Characteristics of studies. As a first step, it is informative to examine the characteristics of the studies from which conclusions about sex differences in aggression shall be drawn. Table 1 shows these study characteristics, summarized separately for (a) the studies for which effect sizes could be calculated and (b) the larger sample of studies, which included studies with calculable effect sizes and studies that reported a nonsignificant sex difference but did not provide information sufficient to compute an effect size. The first nine characteristics are called continuous variables because they were measured on continuous scales, and the remaining six are called categorical variables because each consists of discrete categories into which the studies were classified.

As shown by the central tendencies of the first four continuous variables in Table 1, the studies usually (a) were published

\footnotetext{
${ }^{4}$ In this article, the term respondents designates people who participated in the questionnaire study, and the term subjects designates people who participated in the original experiments reviewed in this metaanalysis.

${ }^{5}$ If such a statistic was presented as a component of a multifactor analysis of variance that included an individual-difference variable other than sex, the error term was reconstituted by adding into the error sum of squares all between-groups sums of squares for terms involving this individual-difference variable (see Glass, McGaw, \& Smith, 1981; Hedges \& Becker, 1986). Sums of squares for manipulated variables were not added to the error term because these variables, especially in laboratory experiments, were sometimes extremely powerful. Consequently, adding their sums of squares to the error sum of squares would have had differing impact on these error terms, across the studies.
} 
Table 1

Summary of Study Characteristics

\begin{tabular}{lcc}
\hline \multicolumn{1}{c}{ Variables } & $\begin{array}{c}\text { Sample with } \\
\text { known effect } \\
\text { sizes }\end{array}$ & All reports \\
\hline & Continuous variables & \\
& & \\
& & \\
$M d n$ publication year & 1974.67 & 1974.38 \\
$M d n$ no. of subjects & 84.50 & 90.20 \\
$M$ percentage of male authors & 58.50 & 58.34 \\
& $(45.66 / 71.34)$ & $(47.97 / 68.71)$ \\
$M d n$ no. of behaviors & 10.00 & 7.75 \\
aggregated & & \\
$M$ sex differences in & & \\
judgments of aggressive & 0.09 & 0.09 \\
behaviors & 0.34 & $(0.05 / 0.13)$ \\
Harm & & 0.33 \\
& & $(0.28 / 0.38)$ \\
Guilt/anxiety & $0.28 / 0.40)$ & 0.25 \\
Danger & 0.20 & $(0.21 / 0.29)$ \\
& $0.17 / 0.24)$ & 0.31 \\
Own behavior & 0.31 & $(0.27 / 0.35)$ \\
& $(0.26 / 0.37)$ & 0.80 \\
Stereotypic & 0.84 & $(0.75 / 0.86)$ \\
& $(0.77 / 0.90)$ &
\end{tabular}

Categorical variables ${ }^{e}$

$\begin{array}{lcc}\text { Setting }^{\mathrm{f}} & 13 / 37 & 26 / 51 \\ \text { Type of aggression }^{\mathrm{B}} & 20 / 30 & 42 / 35 \\ \text { Surveillance }^{\mathrm{h}} & 6 / 30 / 14 & 13 / 43 / 21 \\ \text { Freedom of choice to aggress }^{\mathrm{i}} & 27 / 23 & 50 / 27 \\ \text { Amount of provocation }^{\mathrm{j}} & 29 / 21 & 50 / 27 \\ \text { Sex of target }^{\mathrm{k}} & 4 / 14 / 19 / 13 & 6 / 22 / 31 / 18\end{array}$

Note. $n=50$ for "Sample with known effect sizes" column. $n=77$ for "All reports" column.

a Sample includes studies for which effect sizes were calculable and studies for which they were not. Studies reporting only the direction of the sex difference were excluded. ${ }^{b}$ Values in parentheses are $95 \%$ confidence intervals. ${ }^{\circ}$ Values are positive for differences expected to be associated with greater aggression by men (greater female estimates of harm to others, of guilt and anxiety, and of danger to self; greater male estimate of own likelihood of aggressing). ${ }^{d}$ Values are positive when questionnaire respondents believed men were more aggressive than women. ${ }^{\mathrm{e}}$ Entries are numbers of reports found within each category. ${ }^{f}$ Categories are field/laboratory. ${ }^{8}$ Categories are psychological/physical. ${ }^{\text {h}}$ Categories are private/semiprivate/public. ${ }^{1}$ Categories are free choice/aggression required. ${ }^{j}$ Categories are greater-than-minimal/ minimal. ${ }^{k}$ Categories are female/male/varied/same-as-subject.

relatively recently, (b) involved moderate numbers of subjects, (c) were somewhat more likely to have male authors, and (d) assessed aggression by an index that aggregated a moderate number of behaviors. The means for the next three continuous variables in Table 1 represent the sex differences in questionnaire respondents' beliefs about the consequences of aggression. As shown by the confidence intervals associated with these means, for both samples of studies all of these sex differences differed significantly from 0.00 (the value indicating exactly no sex difference). Thus, women estimated that the aggressive acts would cause more harm to the target than men did. Women also estimated that they would experience more anxiety or guilt and would face more danger from aggressing.

The last two continuous variables in Table 1 reflect question- naire respondents' judgments of the likelihood that the aggressive behaviors would be performed. For both samples of studies, female respondents judged themselves significantly less likely to aggress than male respondents judged themselves, and respondents of both sexes judged the average woman considerably less likely to aggress than the average man.

The summaries of the categorical variables appear next in Table 1. The studies were more often conducted in laboratory than field settings. Psychological and physical aggression were both commonly assessed. Subjects usually were under surveillance either by only the target and/or experimenter (semiprivate), or by additional onlookers (public). Somewhat more studies allowed subjects to choose freely between aggressive and other types of behaviors versus requiring them to engage in an aggressive behavior. Somewhat more studies involved greaterthan-minimal versus minimal amounts of provocation of the aggressor. Designs rarely included only female targets.

Summary of sex-of-subject differences. The summary of the sex-of-subject effect sizes in Table 2 allows one to determine whether there is an overall sex difference in aggression, based on the available reports. A mean effect size that differs significantly

Table 2

Summary of Sex-of-Subject Differences

\begin{tabular}{cc}
\hline \multicolumn{1}{c}{ Criterion } & Values \\
\hline \multicolumn{1}{c}{ Effect size analyses } \\
Known effect sizes $(n=50)$ & \\
$M$ effect size $(M d)$ & 0.40 \\
$95 \%$ CI for $M d$ & $0.28 / 0.51$ \\
$M d n$ effect size & 0.43 \\
$M$ weighted effect size $\left(d_{+}\right)^{\mathrm{a}}$ & 0.29 \\
$95 \%$ CI for $d_{+}$ & $0.24 / 0.34$ \\
Total no. of subjects & 4,879 \\
All reports $(n=77)$ & 0.26 \\
$M$ effect size $(M d)$ & $0.17 / 0.34$ \\
$95 \%$ CI for $M d$ & 6,524 \\
Total no. of subjects &
\end{tabular}

Counting methods

Differences in the male direction $^{\mathrm{b}}$ Frequencies

Exact $p$

Significant differences in the male direction ${ }^{c}$

$50 / 56(.89)$

Note. When all reports were included, a value of 0.00 (exactly no difference) was assigned to sex differences that could not be calculated and were reported as nonsignificant. Effect sizes were calculated for all significant differences. Effect sizes are positive for differences in the male direction and negative for differences in the female direction. $\mathrm{CI}=$ confidence interval.

affect sizes were weighted by the reciprocal of the variance. ${ }^{b}$ Frequencies are number of differences in the male direction divided by the number of differences of known direction. The proportion appears in parentheses. Exact $p$ (one-tailed) is based on the binomial distribution with $p=.5$ (Harvard University Computation Laboratory, 1955). ${ }^{\mathrm{c}}$ Frequencies are the number of significant differences $(p<.05$, two-tailed) in the male direction divided by the total number of comparisons of known significance. The proportion appears in parentheses. Exact $p$ (one-tailed) is based on the binomial distribution with $p=.025$ (Robertson, 1960). There was one significant difference in the female direction. 
from the 0.00 value that indicates exactly no difference suggests an overall sex difference. The mean of the known effect sizes differed from 0.00 in the direction of more aggression by men than women. Weighting each known effect size by the reciprocal of its variance (Hedges \& Olkin, 1985), a procedure that gives more weight to effect sizes that are more reliably estimated, yielded a significant mean effect size in the male direction that was smaller than the unweighted mean. The distribution of the known effect sizes was normal, $W=.97$, with values lower than .95 indicating rejection of the hypothesis of normality at $p<$ .05 (Shapiro \& Wilk, 1965).

There is no completely satisfactory method to compute a mean effect size that takes into account the nonsignificant effects that could not be calculated because of a lack of sufficient information. Nevertheless, one possible solution is to give these nonsignificant effects the value of 0.00 (indicating exactly no sex difference). When this step was taken, the mean (unweighted) effect size decreased but remained significant in the male direction. This mean is reported in Table 2, under "All reports."

As Table 2 shows, the conclusion that men aggressed more than women was supported by counting test results (Rosenthal, 1978 ) demonstrating that .89 , the proportion of reports indicating a sex difference in the male direction (disregarding significance) departed significantly from .50 , the proportion expected under the null hypothesis. As Table 2 also shows, greater aggression by men than women was also consistent with a second counting test, which demonstrated that .34 , the proportion of reports indicating a significant sex difference in the male direction, departed significantly from .025 , the proportion expected under the null hypothesis.

Homogeneity of effect sizes. Although the aggregated sex differences in Table 2 are of interest in relation to our predictions, their importance can be questioned in view of the inconsistency of the findings across the studies. Calculation of a homogeneity statistic $Q$, which has an approximate chi-square distribution with $k-1$ degrees of freedom, where $k$ is the number of effect sizes (Hedges, 1982a; Hedges \& Olkin, 1985), indicated that the hypothesis that the known effect sizes were homogeneous was rejected, $Q=202.44, p<.001$. Therefore, study attributes were used to account for variability in the sex differences. Prediction was attempted only for the 50 known effect sizes because the 0.00 values used to estimate the nonsignificant effects that could not be calculated are too inexact to warrant an attempt to fit statistical models. ${ }^{6}$

Table 3 presents each sex-of-subject effect size that could be calculated, along with the study attributes that predicted these effect sizes and a brief description of each aggressive behavior. Effect sizes are ordered by their magnitude and direction so that the largest sex differences in the male direction appear at the beginning of the table and the largest differences in the female direction appear at the end of the table.

Tests of categorical models. Table 4 presents tests of the univariate categorical models that yielded significant betweenclass effects (analogous to main effects in an analysis of variance) for sex-of-subject differences. In addition to a test of the significance of between-class effects, this approach provides a test of the homogeneity of the effect sizes within each class. If a categorical model were correctly specified (i.e., the data fit the model in the sense that the model sufficiently accounted for the systematic variation in the effect sizes), it would yield a significant between-class effect and homogeneous effect sizes within each class. The between-class effect is estimated by $Q_{B}$, which has an approximate chi-square distribution with $p-1$ degrees of freedom, where $p$ is the number of classes. The homogeneity of the effect sizes within each class is estimated by $Q_{\mathrm{w}_{i}}$, which has an approximate chi-square distribution with $m-1$ degrees of freedom, where $m$ is the number of effect sizes in the class. Table 4 also includes (a) the mean effect size for each class, calculated with each effect size weighted by the reciprocal of its variance, and (b) the $95 \%$ confidence interval for each mean.

Significant between-class effects showed that the tendency for men to aggress more than women was greater in laboratory than field settings and for physical versus psychological aggression. Consistent with the significant between-class surveillance effect, post-hoc comparisons among the mean effect sizes for the three classes (Hedges \& Becker, 1986; Hedges \& Olkin, 1985) showed that the sex difference in semiprivate contexts (target and/or experimenter present) was larger than the sex difference in public contexts (additional onlookers present), $\chi^{2}(2)=9.85, p<$ .01 , and marginally larger than the sex difference in private contexts, $\chi^{2}(2)=4.86, p<.10$. Also, the tendency for men to aggress more than women was significantly larger when aggression was required rather than freely chosen.

Despite these significant between-class effects, none of these categorical models can be regarded as having fit the effect sizes. For each model, the hypothesis of homogeneity of the effect sizes was rejected within each class, except for one category containing only six effect sizes (the private category of the surveillance variable, see Table 4). With the exception of this same category, all of the category means differed from 0.00 and thus indicated a significant sex difference in the male direction. No category mean was positive, which would indicate a difference in the female direction.

Tests of continuous models. Univariate and multivariate tests of continuous models for the sex-of-subject differences were also conducted (Hedges, 1982b; Hedges \& Olkin, 1985). These models are least squares regressions, calculated with each effect size weighted by the reciprocal of its variance. Each such model yields a test of the significance of each predictor as well as a test of model specification, which evaluates whether significant systematic variation remains unexplained in the regression model. The error sum of squares statistic, $Q_{\mathrm{E}}$, which provides this test of model specification, has an approximate chi-square distribution with $k-p-1$ degrees of freedom, where $k$ is the number of effect sizes and $p$ is the number of predictors (not including the intercept).

As Table 5 shows, univariate tests indicated that six of the continuous variables were significantly related to the sex-ofsubject differences. The first of these variables, the number of behaviors aggregated in the aggression measure, was related

\footnotetext{
${ }^{6}$ Alternative calculations representing each study by only one effect size yielded results similar to those we report. No results are presented for the following variables, which did not relate significantly to the magnitude of the sex-of-subject effect size: date of publication, source of publication, percentage of male authors, sex of first author, amount of provocation, and sex of target of aggression.
} 


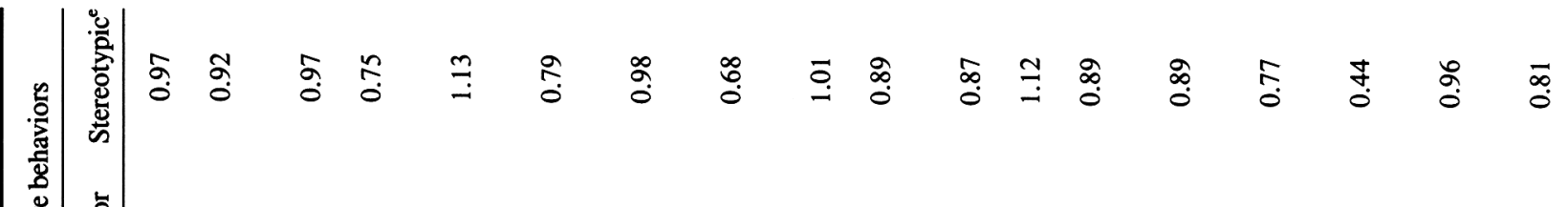

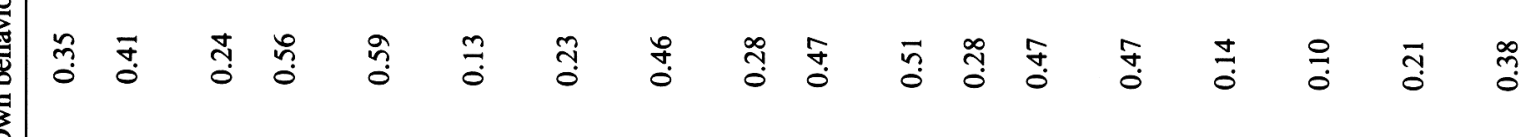

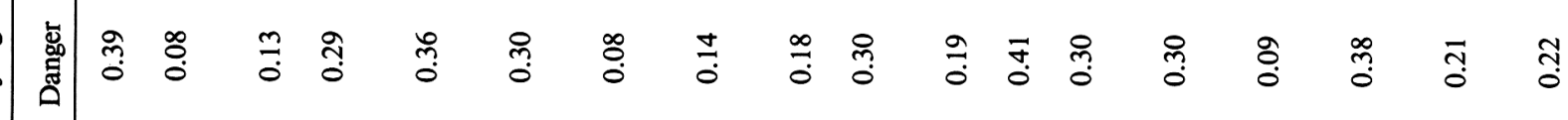

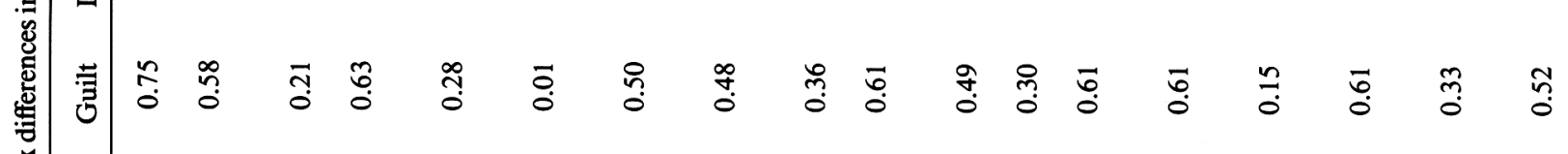

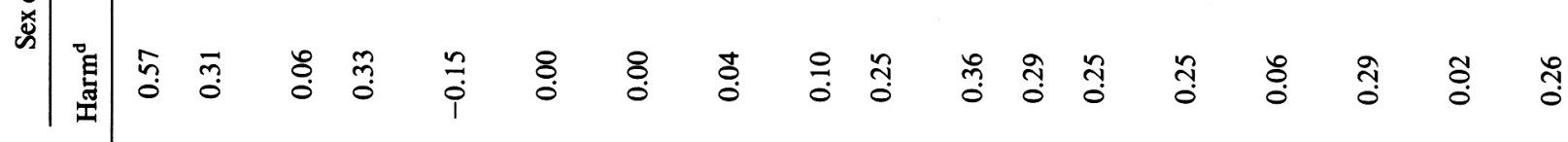

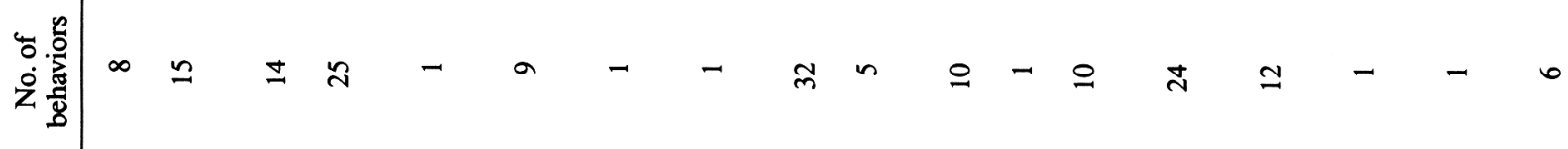

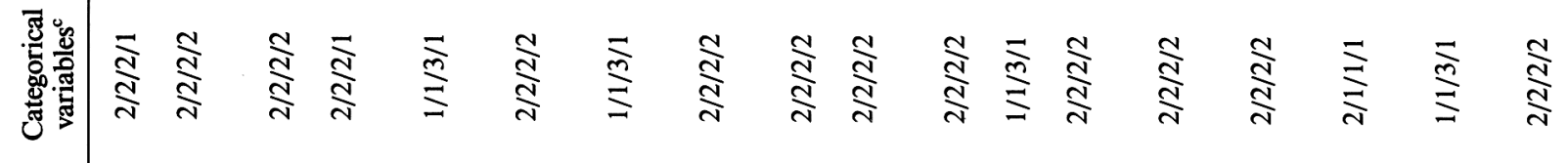

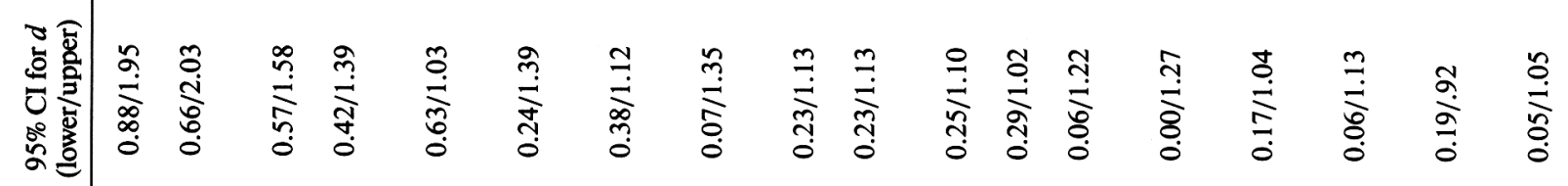

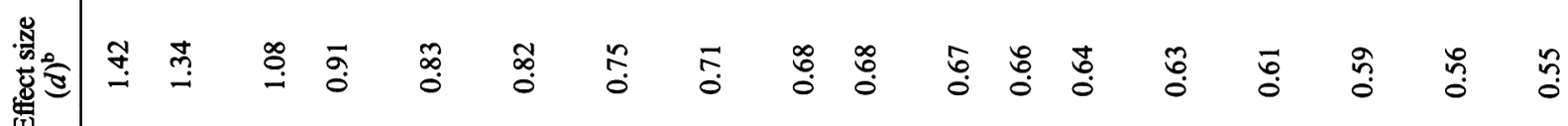

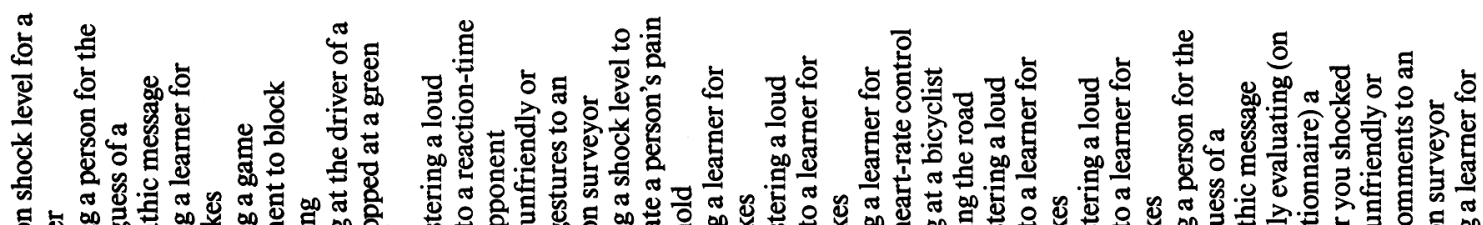

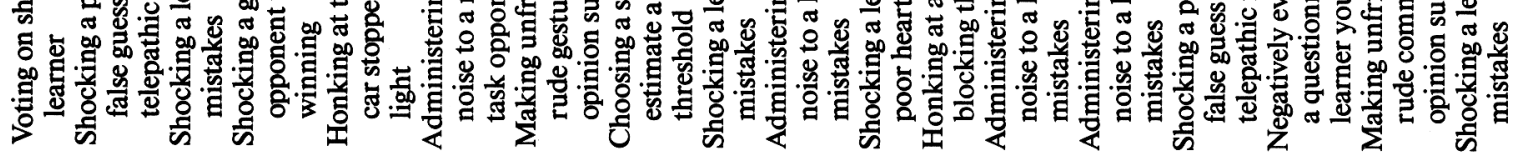




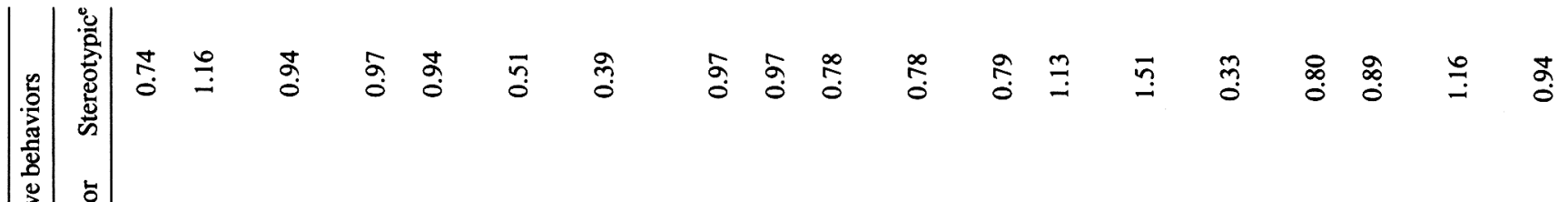

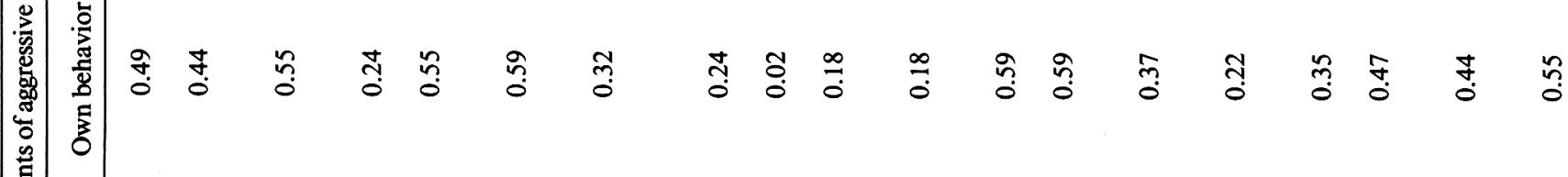

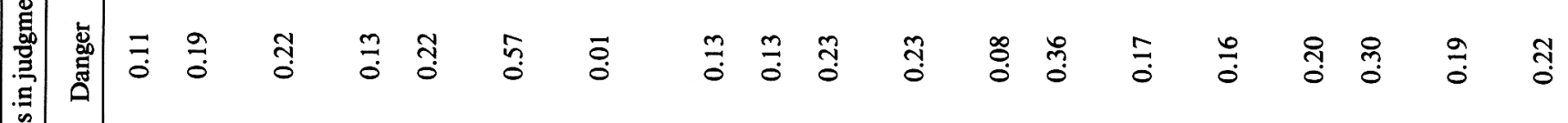

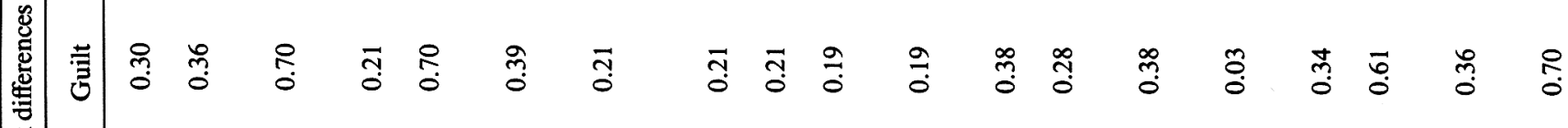

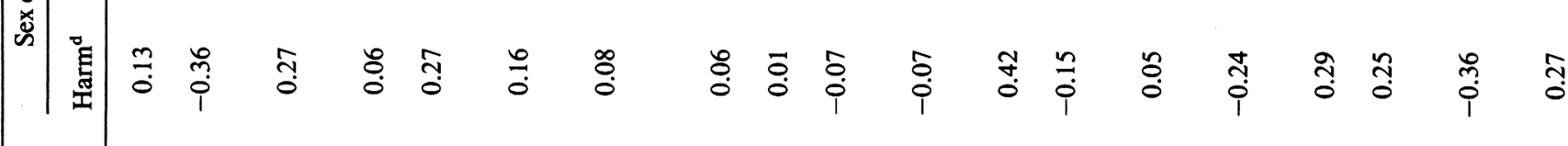

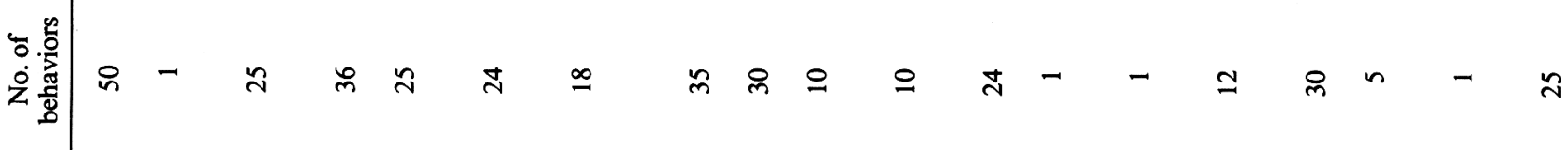

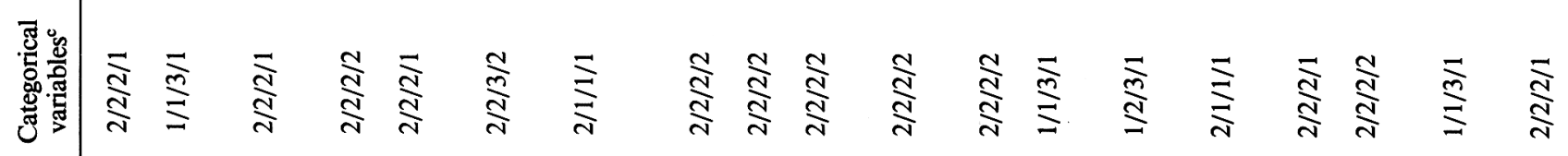

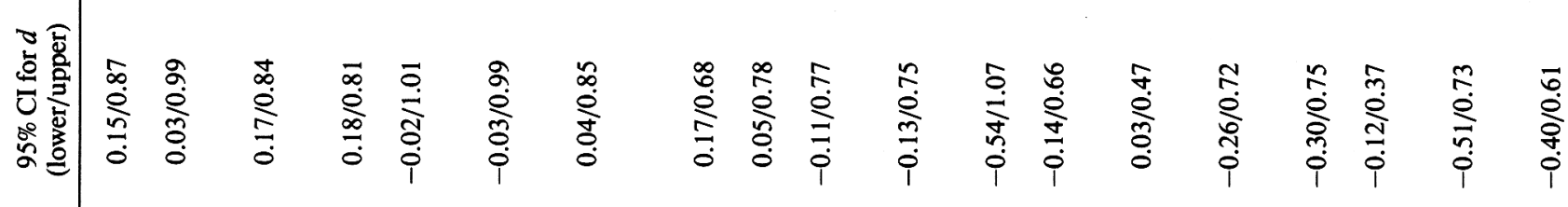

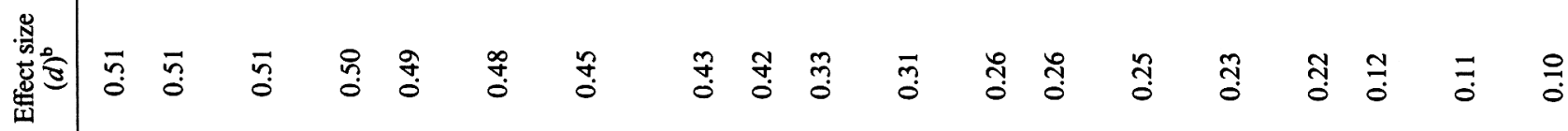

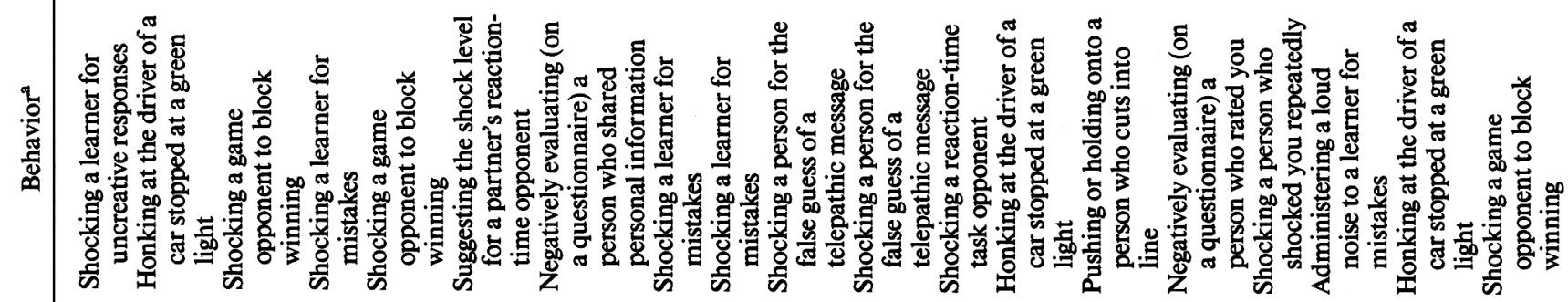

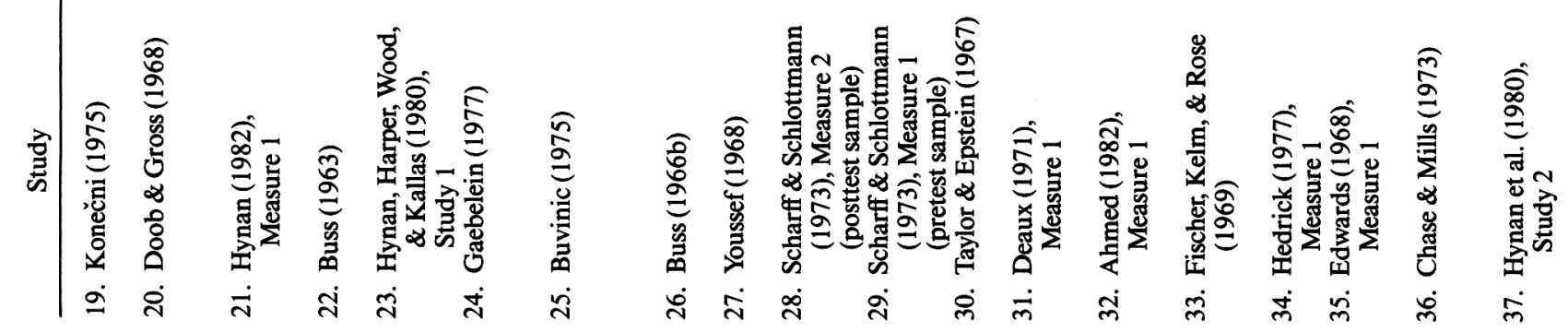




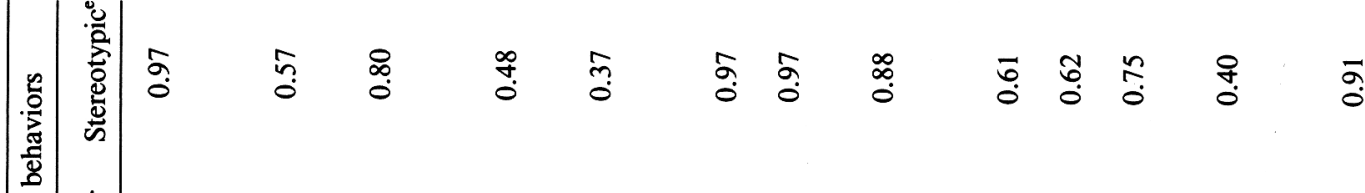

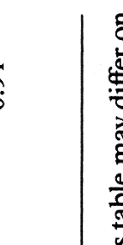

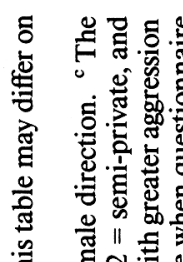

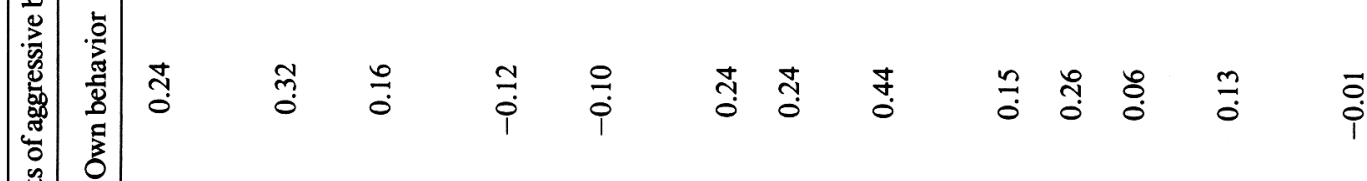

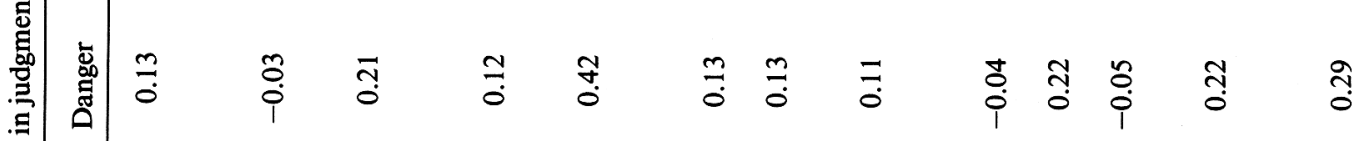
憄

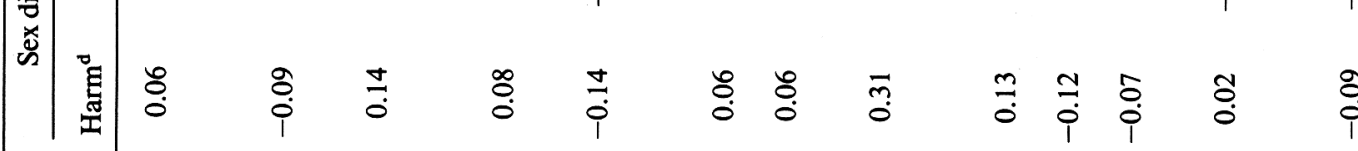
它.

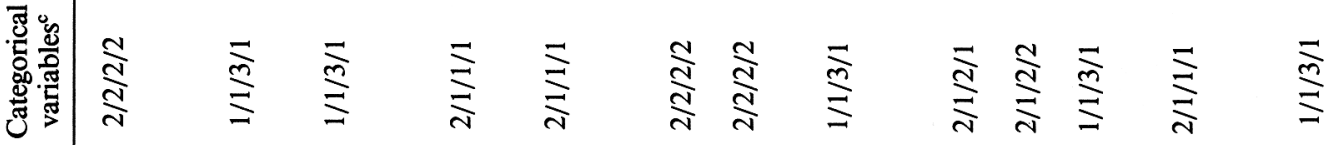

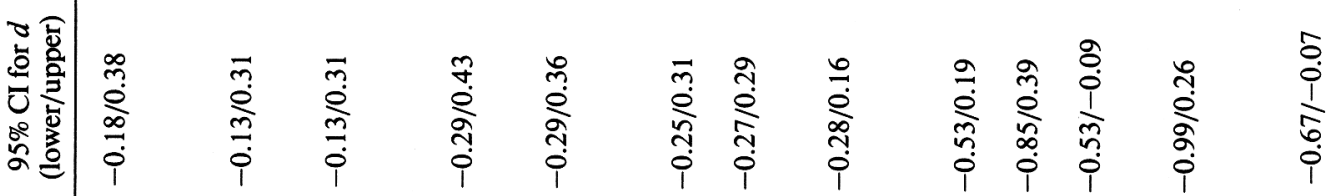

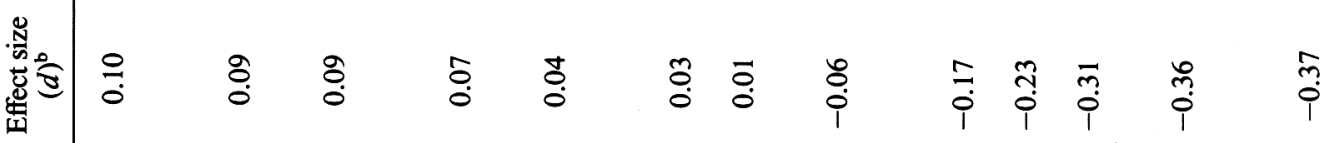

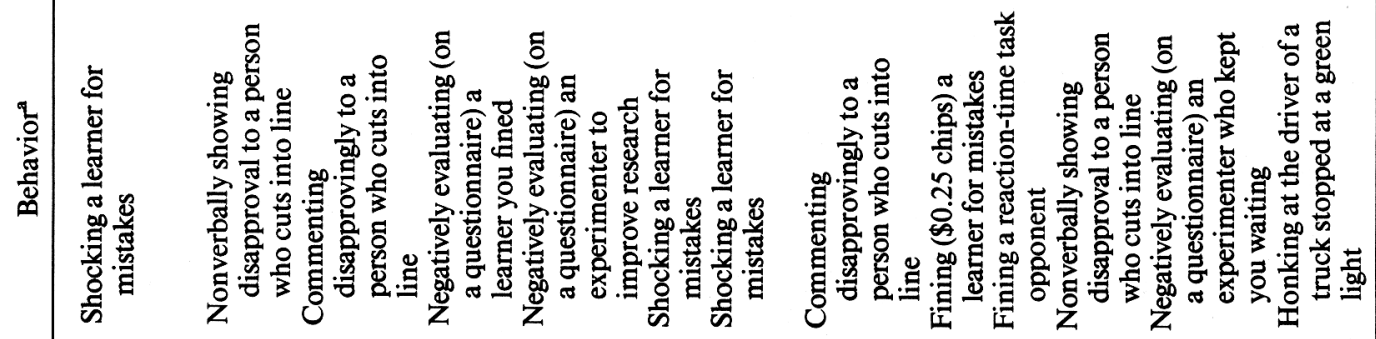
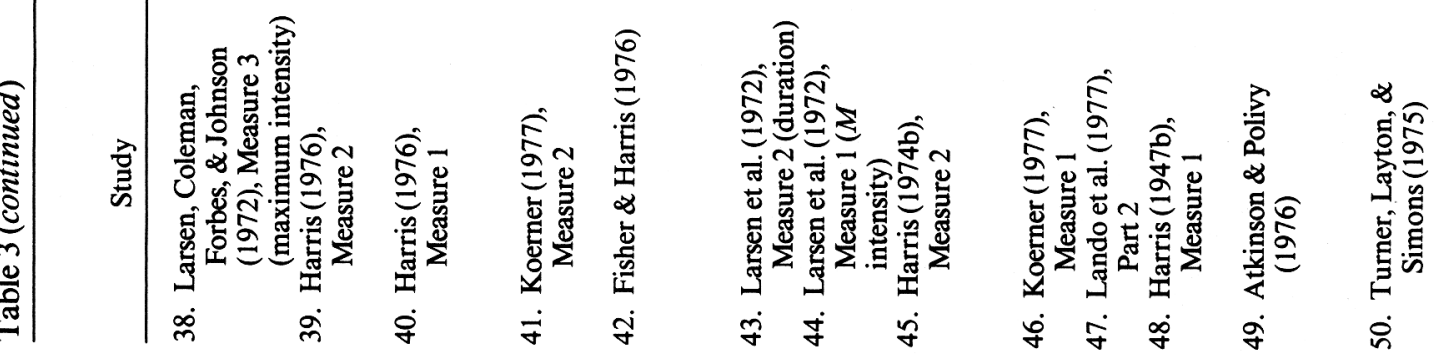
至N

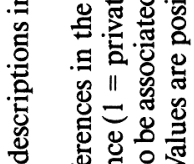
客需焉

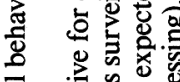
焉

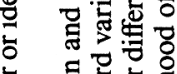

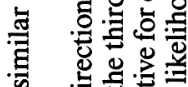

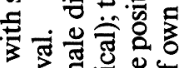

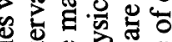

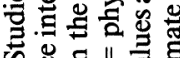
के
额

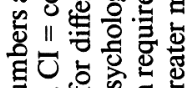

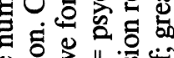
.
它虽

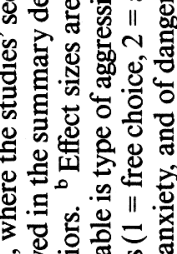

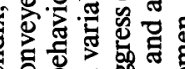

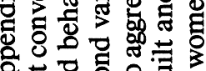

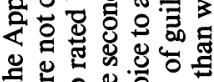

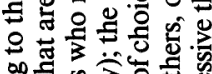

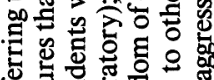

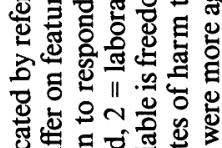

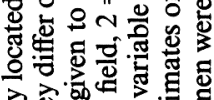

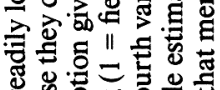

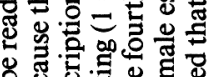

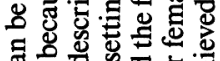

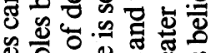
莺.

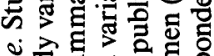

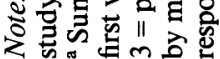


Table 4

Tests of Categorical Models for Sex-of-Subject Effect Sizes

\begin{tabular}{|c|c|c|c|c|c|}
\hline Variable and class & $\begin{array}{c}\text { Between-class } \\
\text { effect }\left(Q_{\mathrm{B}}\right) \\
\end{array}$ & $n$ & $\begin{array}{l}\text { Weighted effect } \\
\text { size }\left(d_{i+}\right)\end{array}$ & $\begin{array}{l}95 \% \text { CI for } d_{i+} \\
\text { (lower/upper) }\end{array}$ & $\begin{array}{l}\text { Homogeneity within } \\
\text { each class }\left(Q_{w_{1}}\right)^{a}\end{array}$ \\
\hline Setting & $7.89^{* *}$ & & & & \\
\hline Type of aggression & $19.27^{* * * *}$ & & & & \\
\hline $\begin{array}{l}\text { Psychological } \\
\text { Physical }\end{array}$ & & $\begin{array}{l}20 \\
30\end{array}$ & $\begin{array}{l}0.18 \\
0.40\end{array}$ & $\begin{array}{l}0.10 / 0.25 \\
0.33 / 0.47\end{array}$ & $\begin{array}{r}112.51^{* * * *} \\
70.66^{* * *}\end{array}$ \\
\hline $\begin{array}{l}\text { Freedom of choice } \\
\text { to aggress }\end{array}$ & $5.62^{*}$ & & & & \\
\hline $\begin{array}{l}\text { Free choice } \\
\text { Aggression required }\end{array}$ & & $\begin{array}{l}27 \\
23\end{array}$ & $\begin{array}{l}0.24 \\
0.37\end{array}$ & $\begin{array}{l}0.18 / 0.30 \\
0.28 / 0.45\end{array}$ & $\begin{array}{r}145.39^{* * * *} \\
51.42^{* * * *}\end{array}$ \\
\hline
\end{tabular}

Note. Effect sizes are positive for differences in the male direction and negative for differences in the female direction. $\mathrm{CI}=$ confidence interval.

a Significance indicates rejection of the hypothesis of homogeneity.

${ }^{*} p<.05{ }^{* *} p<.01{ }^{* * *} p<.001$.

positively to the magnitude of the sex differences: Effect sizes were larger (i.e., a greater tendency for men to aggress more than women) for aggression measures that aggregated larger numbers of behaviors. Effect sizes were also larger to the extent that the following sex differences were obtained in questionnaire respondents' judgments of the aggressive behaviors: Female (com- pared with male) respondents (a) estimated that aggressing would cause more harm to the target, (b) estimated they would experience more guilt or anxiety from aggressing, (c) estimated they would face more danger from aggressing, and (d) judged themselves more likely to aggress. Effect sizes were also larger to the extent that respondents of both sexes judged the average

Table 5

Tests of Continuous Models for Sex-of-Subject Effect Sizes

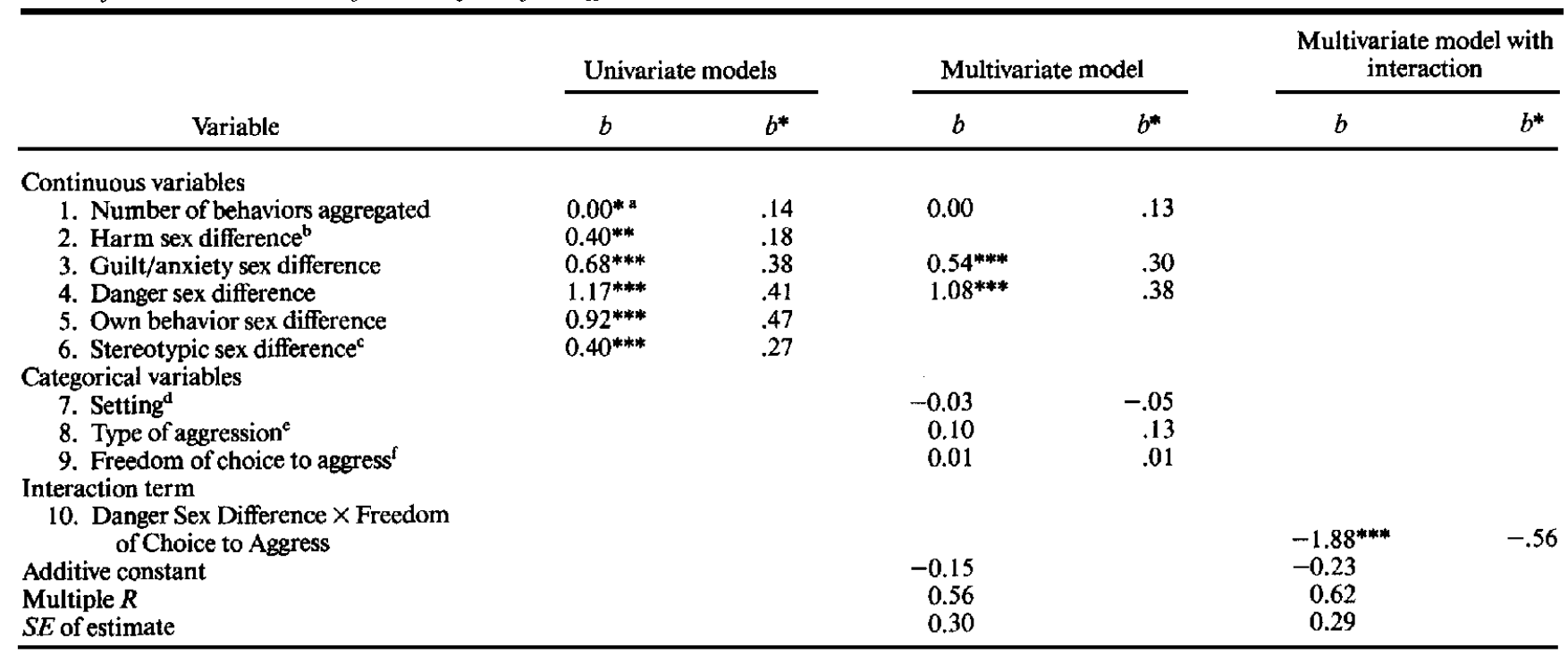

Note. Models are weighted least squares regressions calculated with weights equal to the reciprocal of the variance for each effect size. $b=$ unstandardized regression coefficient. $b^{*}=$ standardized regression coefficient. Effect sizes are positive for differences in the male direction and negative for differences in the female direction. $n=50$.

${ }^{a} b=0.0037, S E(b)=.0019$. ${ }^{b}$ Values are positive for differences expected to be associated with greater aggression by men (greater female estimates of harm to others, of guilt and anxiety, and of danger to self; greater male estimate of own likelihood of aggressing). ${ }^{c}$ Values are positive when questionnaire respondents believed that men were more aggressive than women. ${ }^{d} 0=$ field, $1=$ laboratory. ${ }^{\mathrm{e}} 0=$ psychological, $1=$ physical. ${ }^{\mathrm{f}} 0=$ free choice, 1 = aggression required.

${ }^{*} p<.05 .{ }^{* *} p<.01$. ${ }^{* * *} p<.001$. 
man more likely to aggress than the average woman. Despite these significant relations, none of these models was correctly specified $(p s<.001)$.

To examine the simultaneous impact of the continuous and categorical variables that were significant univariate predictors of effect sizes, we explored various multivariate models. For purposes of these analyses, the categorical variables were dummy coded. The continuous variables constructed from questionnaire respondents' likelihood judgments were excluded from these models because they assessed, not study attributes, but respondents' abilities to predict aggressive behaviors. In addition, the sex difference in respondents' estimates of harm was excluded because of its substantial correlation with the sex difference in their guilt/anxiety estimates, $r(48)=.61, p<.001$. Furthermore, the surveillance variable (dummy coded to reflect the larger effect sizes obtained in semiprivate versus public and private situations) was excluded because of its high correlation with type of aggression, $r(48)=.83, p<.001$, as well as setting, $r(48)=.83, p<.001$.

The first multivariate model in Table 5 entered number of behaviors aggregated, ${ }^{7}$ guilt/anxiety sex difference, danger sex difference, setting, type of aggression, and freedom of choice to aggress. The two significant predictors in this model were the sex differences in guilt/anxiety and in danger. As reflected in the multiple $R$ of .56 , this model was moderately successful in accounting for variability in the magnitude of the effect sizes, although the test of model specification showed that it cannot be regarded as correctly specified, $Q_{\mathrm{E}}=137.72, p<.001$.

Further exploration showed that the sex differences in questionnaire respondents' estimates of harm, guilt/anxiety, and danger predicted the effect sizes considerably better at some levels of the categorical variables than at others. Prediction was especially effective (a) from harm ratings when the setting was the laboratory and aggression was physical, (b) from guilt/anxiety ratings when aggression was not required, and (c) from danger ratings when the setting was the field and aggression was not required. The effects of the resulting interactions are illustrated by the inclusion of the largest of the interactions in the second multivariate model in Table 5.

This second model included the Danger Sex Difference $\times$ Freedom of Choice to Aggress interaction. Consistent with this interaction, only when subjects were not required to aggress were effect sizes larger to the extent that male respondents estimated that they faced less danger from enacting an aggressive behavior. Consistent with the hierarchical analysis of interactions (see Cohen \& Cohen, 1983), the main effects were partialed from the interaction but the interaction was not partialed from the main effects. Therefore, for this second model, regression coefficients for the main effects are not reported because they are not interpretable. This second model proved moderately successful in accounting for variability in effect sizes, as shown by its multiple $R$ of .62 , although it also cannot be regarded as correctly specified, $Q_{\mathrm{E}}=125.75, p<.001$. Additional interaction terms were not added to this model because of the large number of predictors and the multicollinearity that resulted.

\section{Sex-of-Target Differences}

A subset of the studies reporting sex-of-subject differences in aggression varied the sex of the target and reported a test of this
Table 6

Summary of Sex-of-Target Differences

\begin{tabular}{|c|c|c|c|}
\hline \multicolumn{2}{|l|}{ Criterion } & \multicolumn{2}{|l|}{ Values } \\
\hline \multicolumn{4}{|c|}{ Effect size analyses } \\
\hline $\begin{array}{l}\text { Known effect sizes }(n=20) \\
M \text { effect size }(M d) \\
95 \% \text { CI for } M d \\
M d n \text { effect size } \\
M \text { weighted effect size }\left(d_{+}\right)^{a} \\
95 \% \text { CI for } d_{+} \\
\text {Total no. of subjects } \\
\text { All reports }(n=26) \\
M \text { effect size }(M d) \\
95 \% \text { CI for } M d \\
\text { Total no. of subjects }\end{array}$ & & $\begin{array}{c}0.32 \\
0.06 / 0.57 \\
0.29 \\
0.13 \\
0.05 / 0.20 \\
1,745 \\
\\
0.24 \\
0.04 / 0.44 \\
2,349\end{array}$ & \\
\hline \multicolumn{4}{|c|}{ Counting methods } \\
\hline $\begin{array}{l}\text { Differences in the male } \\
\text { direction }^{\mathrm{b}} \\
\text { Significant differences in } \\
\text { the male direction }^{\mathrm{c}}\end{array}$ & $\begin{array}{l}\text { Frequencies } \\
20 / 23(.87) \\
10 / 26(.38)\end{array}$ & & $\begin{array}{l}\text { Exact } p \\
<.001 \\
<.001\end{array}$ \\
\hline
\end{tabular}

Note. When all reports were included, a value of 0.00 (exactly no difference) was assigned to sex differences that could not be calculated and were reported as nonsignificant. Effect sizes were calculated for all significant differences. Effect sizes are positive for differences in the male direction and negative for differences in the female direction. $\mathrm{CI}=$ confidence interval.

${ }^{a}$ Effect sizes were weighted by the reciprocal of the variance. ${ }^{b}$ Frequencies are the number of differences in the male direction divided by the total number of differences of known direction. The proportion appears in parentheses. Exact $p$ (one-tailed) was based on the binomial distribution with $p=.5$ (Harvard University Computation Laboratory, 1955). ${ }^{\mathrm{c}}$ Frequencies are the number of significant differences $(p<.05$, two-tailed) in the male direction divided by the total number of comparisons of known significance. The proportion appears in parentheses. Exact $p$ (one-tailed) was based on the binomial distribution with $p=.025$ (Robertson, 1960). There were three significant differences in the female direction.

manipulation's impact. Table 6 presents a summary of these sex-of-target effect sizes. The means of the effect sizes deviated from 0.00 in the direction of greater aggression toward men than women. Means smaller than the unweighted mean resulted from (a) weighting each known effect size by the reciprocal of its variance or (b) including, as 0.00 values, the nonsignificant differences that were not calculable as effect sizes. The distribution of the known effect sizes was normal, $W=.96$, with values lower than .90 indicating rejection of the hypothesis of normality at $p<.05$ (Shapiro \& Wilk, 1965). The sex-of-target effect sizes showed a nonsignificant negative relation to the sex-ofsubject effect sizes for the 13 reports for which both effect sizes could be calculated, $r(11)=-.25, n s$.

The conclusion that subjects aggressed more against men

\footnotetext{
${ }^{7}$ Also, number of behaviors did not relate to the effect sizes on a nonlinear basis or to the variability of the effect sizes. Given the nonsignificance of number of behaviors as a predictor in the multiple-regression models, we do not discuss it further.
} 
Table 7

Tests of Categorical Models for Sex-of-Target Effect Sizes

\begin{tabular}{|c|c|c|c|c|c|}
\hline Variable and class & $\begin{array}{c}\text { Between-class } \\
\text { effect }\left(Q_{\mathrm{B}}\right)\end{array}$ & $n$ & $\begin{array}{l}\text { Weighted effect } \\
\text { size }\left(d_{i+}\right) \\
\end{array}$ & $\begin{array}{l}95 \% \text { CI for } d_{i+} \\
\text { (lower/upper) }\end{array}$ & $\begin{array}{l}\text { Homogeneity within } \\
\text { class }\left(Q_{w_{t}}\right)^{\mathrm{a}} \\
\end{array}$ \\
\hline Setting & $13.83^{* *}$ & & & & \\
\hline $\begin{array}{l}\text { Field } \\
\text { Laboratory }\end{array}$ & & $\begin{array}{r}11 \\
9\end{array}$ & $\begin{array}{l}0.03 \\
0.37\end{array}$ & $\begin{array}{r}-0.06 / 0.13 \\
0.29 / 0.45\end{array}$ & $\begin{array}{c}175.03^{* *} \\
9.92\end{array}$ \\
\hline Type of aggression & $14.63^{* * *}$ & & & & \\
\hline $\begin{array}{l}\text { Psychological } \\
\text { Physical }\end{array}$ & & $\begin{array}{r}13 \\
7\end{array}$ & $\begin{array}{l}0.04 \\
0.40\end{array}$ & $\begin{array}{r}-0.04 / 0.13 \\
0.24 / 0.56\end{array}$ & $\begin{array}{c}175.47^{* *} \\
8.69\end{array}$ \\
\hline Surveillance $^{\mathrm{b}}$ & $80.22^{m *}$ & & & & \\
\hline $\begin{array}{l}\text { Semiprivate } \\
\text { Public }\end{array}$ & & $\begin{array}{r}13 \\
6\end{array}$ & $\begin{array}{r}0.55 \\
-0.19\end{array}$ & $\begin{array}{c}0.43 / 0.67 \\
-0.30 /-0.09\end{array}$ & $\begin{array}{l}21.66^{*} \\
94.16\end{array}$ \\
\hline $\begin{array}{l}\text { Freedom of choice } \\
\text { to aggress }\end{array}$ & $10.84^{* *}$ & & & & \\
\hline $\begin{array}{l}\text { Free choice } \\
\text { Aggression required }\end{array}$ & & $\begin{array}{r}13 \\
7\end{array}$ & $\begin{array}{l}0.05 \\
0.37\end{array}$ & $\begin{array}{r}-0.04 / 0.14 \\
0.20 / 0.53\end{array}$ & $\begin{array}{l}178.83^{* *} \\
9.12\end{array}$ \\
\hline Amount of provocation & $35.44 * *$ & & & & \\
\hline $\begin{array}{l}\text { Minimal } \\
\text { More than minimal }\end{array}$ & & $\begin{array}{r}8 \\
12\end{array}$ & $\begin{array}{r}-0.16 \\
0.37\end{array}$ & $\begin{array}{c}-0.26 /-0.06 \\
0.25 / 0.50\end{array}$ & $\begin{array}{r}103.74^{* * *} \\
59.61^{* * *}\end{array}$ \\
\hline
\end{tabular}

Note. Effect sizes are positive for differences in the male direction and negative for differences in the female direction. $\mathrm{CI}=\mathrm{confidence}$ interval.

a Significance indicates rejection of the hypothesis of homogeneity. ${ }^{b}$ The private category contained only one effect size.

${ }^{*} p<.05 .{ }^{* *} p<.001$.

than women was also supported by the results of the two counting tests shown in Table 6. Thus, the proportion of reports indicating a sex-of-target difference in the male direction, .87 , departed significantly from .50. Also, the proportion of reports indicating a significant sex-of-target difference in the male direction, .38 , departed significantly from .025 .

Because the hypothesis that the known effect sizes were homogeneous was rejected, $Q=198.79, p<.001$, the study attributes were used to account for variability in the effect sizes. ${ }^{8}$

Tests of categorical models. Table 7 presents tests of univariate categorical models that yielded significant between-class effects for sex-of-target differences. The significant betweenclass effects showed that the tendency for subjects to aggress more against men than women was greater (a) in laboratory than field settings, (b) for physical than psychological aggression, (c) in semiprivate (target and/or experimenter present) than public contexts (additional onlookers present), (d) when aggression was required rather than freely chosen, and (e) with greater-than-minimal versus minimal provocation. Although for three of these categorical models the hypothesis of homogeneity of the effect sizes was not rejected within one of the classes (Table 7), considerable unexplained variability remained within the other classes.

\section{Other Analyses}

Univariate tests of continuous models were also examined for the sex-of-target effect sizes. Although the variables constructed from our questionnaire respondents' ratings of the aggressive behaviors were significantly related to the sex-of-target effect sizes, we do not report these analyses in this article. Because we had formulated hypotheses only for the impact of these variables on sex-of-subject effect sizes, interpretation of these relations is difficult. The inconsistency of these relations across the various questionnaire variables and the relatively small number of available effect sizes $(n=20)$ further clouded interpretation. The small number of effect sizes also precluded testing multivariate continuous models.

Some studies that varied the sex of the target also reported enough information to calculate sex-of-target differences separately for female and male subjects and sex-of-subject differences separately for female and male targets. Unfortunately, only a small number of each of these types of effect sizes (10 or fewer) could be calculated. As a consequence, confidence intervals for the mean effect sizes were quite large, and we are reluctant to interpret these means. In addition, the aggregated sexof-target effect sizes did not differ much between the female and male subjects, nor did the aggregated sex-of-subject effect sizes differ much between the female and male targets. Therefore, these additional analyses did not yield much new information.

\section{Discussion}

\section{Magnitude of Mean Sex Differences}

As predicted, men delivered and received more aggression than women. The mean weighted sex-of-subject effect size based on the known effect sizes was 0.29: less than one-third of a standard deviation in the direction of greater aggression by men than women. Because the additional sex differences reported as nonsignificant that could not be estimated were no doubt smaller on the average than the known differences, 0.29

\footnotetext{
${ }^{8}$ No results are presented for the following variables, which did not relate significantly to the magnitude of the sex-of-target effect sizes: date of publication, source of publication, and number of behaviors. Although sex-of-target effect sizes were significantly different in male-authored versus female-authored articles, the small number of effect sizes from male-authored articles $(n=5)$ makes us hesitant to present this finding.
} 
should be regarded as an upper bound of the aggregated sex-ofsubject differences in the sample of studies. Similarly, the weighted mean sex-of-target effect size of 0.13 - only oneeighth of a standard deviation in the direction of greater aggression against men than women-should be regarded as an upper bound of this aggregated sex difference. These mean effect sizes correspond to point-biserial correlations of .14 between subject sex and aggression and .06 between target sex and aggression.

Although our mean sex-of-subject effect size is smaller than the mean of 0.50 reported by Hyde (1986), the preponderance of studies with child subjects in Hyde's review probably accounts for this discrepancy. According to Hall's (1984) survey of all available sex-of-subject meta-analyses, the magnitude we obtained for the aggression sex difference is smaller than that reported for many other sex differences in social behaviors and psychological attributes. Aggression sex differences are apparently not especially large on the average among adult subjects, compared with sex differences in other social behaviors such as helping and nonverbal behaviors. Although Maccoby and Jacklin (1974) concluded that aggression is the only social behavior for which there is clear-cut evidence of a sex difference, our quantitative review of the social psychological literature suggests that aggression is not one of the larger sex differences among adult research subjects.

Validity considerations. Interpretations of these aggregated effect sizes should take into account possible threats to the validity of the sex differences they suggest (see Eagly, 1986). For example, a tendency to publish studies with statistically significant sex difference findings might have biased available findings toward larger effect sizes (Greenwald, 1975; Lane \& Dunlap, 1978). Yet, as in research on many other social behaviors (e.g., helping, influenceability), sex difference findings typically received little emphasis in the studies in the aggression literature and therefore were unlikely to affect publishability. Also, the normality of the distributions of both the sex-of-subject and sex-of-target effect sizes suggests that publication bias is not a major problem in this meta-analysis (see Light \& Pillemer, 1984).

The most serious reservations concerning the construct validity and external validity of our aggregated sex difference findings stem from the focus of the social psychological aggression literature on interactions with strangers in relatively few types of short-term encounters (see Krebs \& Miller, 1985). In view of this limitation, it is relevant to examine sex differences reported in research in which aggressive behavior has been studied in other social contexts. For example, men's greater participation in crime (Bowker, 1978) might be relevant to sex differences in aggression. Also of possible relevance are women's and men's apparently similar rates of violent behavior toward their spouses, although women are more likely to be injured in such encounters (e.g., Straus, Gelles, \& Steinmetz, 1980). Yet feminist analyses of family violence (see Breines \& Gordon, 1983) assert that spouse abuse is asymmetric because it is generally initiated by husbands and functions to maintain male dominance in the marriage. Moreover, women's violence toward their husbands is more likely to be in self-defense than is men's toward their wives (Straus, 1980). Research on family violence also suggests that mothers and fathers participate about equally in child abuse (Breines \& Gordon, 1983). However, in interpret- ing this finding, women's greater responsibility for child care should be taken into account because it exposes them to greater provocation and opportunity to aggress. Sex differences in psychological aggression have been studied relatively little in close or long-term relationships, although investigations of conflict in couples have suggested that in seeming contrast to the typical direction of aggression sex differences, women tend to confront conflict and men tend to avoid it (Peplau, 1983). Yet, based on several self-report studies, Frost and Averill (1982) concluded that despite few differences in women's and men's everyday experience of anger, women may be less overtly aggressive when expressing their anger. Although the implications of these diverse findings for sex differences in aggression require further exploration, the absence of an obviously consistent sex difference suggests caution in drawing firm conclusions about the relative aggressiveness of women and men outside of the relatively narrow band of settings used in the aggression research we have reviewed in this meta-analysis.

Related to our concerns about the limited social contexts of social psychological aggression research are the questions that a number of scholars have raised about the construct validity of the findings generated by the popular laboratory research paradigms. For this meta-analysis, we accepted into our sample nearly all studies that researchers regarded as investigating adult aggression (provided that these studies also met our criteria for an interpretable sex difference, see the Method section). As other commentators have pointed out (Bertilson, 1983; Geen, 1976; Rajecki, 1983), there is little internal evidence in most such studies that the dependent measure is primarily an aggressive behavior motivated by the harmful intent central to most social psychological definitions of aggression (e.g., Baron, 1977; Berkowitz, 1964). For example, an ostensibly aggressive behavior may reflect demand characteristics of the experiment (Schuck \& Pisor, 1974) or the perpetrator's desire to either help the target person (Baron \& Eggleston, 1972) or reciprocate a hostile action (Tedeschi, 1983; Tedeschi, Smith, \& Brown, 1974). Although the validity of laboratory aggression research has been defended (e.g., Berkowitz \& Donnerstein, 1982), for the most part these important issues remain unresolved. Moreover, as shown by dictionary definitions of aggression, nonpsychologists consider that aggression encompasses forceful actions intended to dominate or master, regardless of their harmful intent. The resulting discrepancy between popular and social psychological definitions of aggression also suggests caution in generalizing from this meta-analysis to conclusions about sex differences in the broad range of behaviors ordinarily considered aggressive.

\section{Social Roles and the Prediction of Sex Differences in Aggression}

Generally compatible with our social-role analysis are our findings that sex differences in aggression are relatively small when averaged and quite inconsistent across studies. We argued, for example, that the male gender role, although more supportive of aggressiveness than the female gender role, discourages aggressiveness under certain circumstances. Because of such complexities of normative regulation of aggression, considerable variability in the magnitude of sex differences in aggression 
would be expected, along with a relatively small mean difference. As in the case of helping behaviors (Eagly \& Crowley, 1986 ), this relatively small mean was created by averaging heterogeneous effects, some of which are quite large. Given these results, mean effect sizes implying a sex difference of a certain magnitude are less important than successful prediction of variability in the effect sizes.

Our social-role analysis proved moderately successful in suggesting specific predictors of sex differences in aggression. With respect to our categorical study attributes, the strongest predictor was whether aggression caused physical or psychological harm to its target. Thus, supporting our analysis, the tendency for men to aggress more than women was more pronounced when the situation provided an opportunity for physical rather than psychological aggression.

The greater aggressiveness of men than women was also more pronounced (a) in the laboratory than in the field, (b) in semiprivate (surveillance by the experimenter and/or target) versus public or private contexts, and (c) when aggression was required rather than freely chosen. Although these additional categorical variables have some relevance to our theoretical analysis (see our introduction), we are reluctant to interpret these findings because these variables were confounded to varying degrees with type of aggression (physical vs. psychological) and with one another. When the categorical variables that were significantly related to the aggression sex difference on a univariate basis were simultaneously entered as dummy-coded predictors in a multiple-regression model, only type of aggression remained a significant predictor. Therefore, type of aggression warrants primary emphasis in the interpretation of the impact of the categorical variables on sex differences in aggression.

Sex differences in beliefs about the consequences of aggression. Our social-role analysis suggested that (a) women's and men's beliefs about the consequences of aggression would differ in general and (b) variability in the magnitude of these differences in perceived consequences would account for the variability in sex differences in aggression. Consistent with expectancy-value theories (e.g., Feather, 1982; Fishbein \& Ajzen, 1975), these hypotheses presume that aggression is cognitively controlled in terms of its expected consequences.

As expected, male (vs. female) questionnaire respondents reported that their aggressive behavior would cause them less guilt and anxiety about others' suffering and would cause less harm to others. In addition, the guilt/anxiety and harm sex differences were substantial univariate predictors of the aggression effect sizes. Moreover, women (more than men) believed that their aggressive behaviors were likely to pose dangers to themselves, and the danger sex difference was a significant predictor of the effect sizes. As in Eagly and Crowley's (1986) meta-analysis of helping behavior, the sex difference in perceived danger to oneself was one of the most substantial predictors of the effect sizes.

It is noteworthy that sex differences in beliefs about the consequences of aggression emerged as more important predictors under some conditions than others. Most important, the guilt/ anxiety and danger sex differences predicted sex differences in aggression more effectively when aggressive behavior was not required. Perhaps the optional quality of aggression in such situations favors systematic weighing of the consequences of ag- gressing. These and other interactions involving the predictors constructed from our questionnaire respondents' judgments suggest that in many natural settings, which typically do not require aggressive behavior, people sometimes behave in ways that are markedly sex-typed. Thus, in some circumstances, men aggress considerably more than women to the extent that women believe that an aggressive act has more strongly negative outcomes than men believe it has.

Our multivariate models showed that only the sex differences in the perceived consequences of aggression (guilt/anxiety and danger) remained significant when both the categorical and continuous variables were entered in the regression equation. Furthermore, this regression equation did not account for significantly more variation than one entering only sex differences in guilt/anxiety and danger. These outcomes are consistent with the conclusion that the impact of the contextual variables on aggression sex differences was mediated by sex differences in the perceived consequences of aggression. Supporting this interpretation, an analysis of variance partitioning the studies on type of aggression, the most important categorical predictor, found that physical (vs. psychological) aggression was associated with significantly larger sex differences in ratings of guilt/ anxiety and harm to others ( $p s<.001)$, and with nonsignificantly larger sex differences in danger to self $(p=.13)$. The sex difference in danger to self might have been more strongly related to type of aggression had the majority of the studies on physical aggression not been conducted in laboratories, which are presumed to provide protection for experimental subjects who perpetrate aggression.

Sex-of-target differences. As we suggested in the introduction, overall sex-of-target effects are difficult to predict. In our sample of studies, subjects aggressed slightly more against men than women, yet the effect sizes were inconsistent across studies. The magnitude of these sex-of-target effect sizes was related to the same four categorical study variables that were significant predictors of the sex-of-subject effect sizes as well as to the amount of provocation. Thus, the tendency for men to be aggressed against more than women was stronger (a) in the laboratory than in the field, (b) with physical versus psychological aggression, (c) in semiprivate rather than public contexts, (d) when aggression was required as opposed to freely chosen, and (e) with more-than-minimal versus minimal provocation. Nevertheless, the confounding of these variables as well as the relatively small number of effect sizes makes a definitive interpretation of these relations difficult.

\section{Biological Theories of Sex Differences in Aggression}

Aggression in general and aggression sex differences in particular have often been analyzed in terms of underlying biological mechanisms (e.g., Hamburg \& Trudeau, 1981; Simmel, Hahn, $\&$ Walters, 1983). Yet the adequacy of the research evidence that human sex differences in aggression are biologically mediated has been contested by some reviewers (Bleier, 1984; Pleck, 1981) and accepted by others (e.g., Maccoby \& Jacklin, 1974; Parke \& Slaby, 1983). Without taking a position on the strength of the evidence for the existence of biological mediation, we formulated a social psychological analysis for the meta-analysis because of social-role theory's assumption that social norms as 
well as sex-typed beliefs and abilities are the proximal determinants of sex differences in adult aggressive behavior and that biological causes are for the most part only indirectly relevant (see Eagly, in press). Although the social-role framework should be more successful in explaining variability in sex-difference findings than are biological theories, the social-role account does not invalidate alternative theories, and the findings of this meta-analysis do not bear directly on the issue of biological versus environmental causation.

Despite these reservations, comparisons between the child and adult research literatures on aggression have some relevance to disentangling biological and environmental causes. Although such comparisons are perilous because of differences in research methods, the relatively small average effect size yielded by our meta-analysis of the adult literature is consistent with other reviewers' claims that the aggression sex difference is larger among children than adults (Hyde, 1984; Rohner, 1976). One may speculate whether this possible difference in the magnitude of the overall sex difference is due to a lessening of biological control of aggression and an increase of normative regulation as people develop. In particular, our social-role theory suggests that the male gender role, despite encouraging aggressiveness overall, imposes limits on aggressive behavior and that the female gender role, despite discouraging aggressiveness overall, may in its modern form encourage self-assertive behavior. In addition, other social roles occupied by women and men encourage or discourage aggressiveness, and, even if they encourage aggression, regulate the conditions under which role occupants may behave aggressively. The consequent restraint of male aggressiveness under many circumstances and probable encouragement of female aggressiveness may result in an overall lessening of aggression sex differences in adulthood.

\section{Conclusion}

In general, this meta-analysis shows that men are more aggressive than women and that this sex difference is more pronounced for physical than psychological aggression. It also demonstrates that women and men think differently about aggression and suggests that these differing beliefs are important mediators of sex differences in aggressive behavior. Women reported more guilt and anxiety as a consequence of aggression, more vigilance about the harm that aggression causes its victims, and more concern about the danger that their aggression might bring to themselves. Women's and men's beliefs about the consequences of aggression diverge considerably, when, for example, the situation provides an opportunity to aggress physically rather than psychologically. In such situations, sex differences in aggression are often relatively large.

Success of predictions. The overall success in predicting aggression sex differences using study attributes is best described as moderate, even though this success was greater than that of the questionnaire respondents' implicit theories, which were assessed from these respondents' estimates of the likelihood of their own and others' aggressive behaviors (see Table 5). Multivariate models, which excluded these likelihood measures, accounted for approximately $40 \%$ of the variability in the available findings. Given the many subtle differences between the research paradigms in this literature, it is probably unreason- able to expect to account for all of the systematic variation between effect sizes. Nevertheless, the absence of correctly specified models suggests caution in interpreting the relations that were obtained (Hedges \& Olkin, 1985). Moreover, the $40 \%$ of variability explained is substantially lower than the approximately $70 \%$ of variability that Eagly and Crowley (1986) accounted for in their meta-analysis of helping behavior, which used methods similar to those of the our meta-analysis. This lesser success could be due to any of several factors, possibly including (a) a less adequate social psychological analysis for this aggression review than for the helping review (Eagly \& Crowley, 1986) and (b) limitations in the validity of the measures that social psychologists have devised for studying aggression (see the section on Validity considerations). Yet this $40 \%$ figure is quite respectable among published meta-analyses on psychological topics, which have typically accounted for less variability in effect sizes.

Comparisons with Frodi et al.'s conclusions. Our conclusions about sex-of-subject differences can be compared with those of Frodi et al.'s (1977) narrative review, which was brought up to date by White (1983) and Macaulay (1985) with little change in conclusions. Frodi et al.'s review and the subsequent articles are similar to our own review in their focus on the social psychological literature on adult aggressive behavior.

Our generalizations differ from those of Frodi et al. in the importance we accord to whether aggression has a physical or psychological impact on its victims and in the unimportance we accord to the amount of provocation for aggression. Although we agree with Frodi et al.'s emphasis on aggression guilt and anxiety as psychological mediators of aggression sex differences, our conclusions are stronger with respect to empathy mediation. Our conclusion that anticipated danger to oneself is an important mediator raises questions about their conclusion that fear of retaliation, surely a major component of perceived danger, is an unimportant mediator.

Frodi et al.'s (1977) generalization that women are not always less aggressive than men is rendered more precisely by our meta-analytic methods. Indeed, effect sizes were heterogeneous overall and often quite small. When averaged, they yielded a relatively small mean effect size. Yet reversals of the stereotypic sex difference were relatively rare: In only 6 of the 56 comparisons for which direction could be discerned were women more aggressive than men. Moreover, there was no category of studies in which women were more aggressive than men (see Table 4). It should also be noted that our conclusion with respect to sexof-target differences is somewhat weaker than that of Frodi et al., given the small mean effect size we obtained. Finally, we did not address a number of Frodi et al.'s conclusions (e.g., that there are sex differences in the cues that cause anger) because they did not lend themselves to quantitative analysis within the sample of studies we examined.

Agentic bias in research. One important implication of our review is that the best known and most popular methods for studying human aggression-the teacher-learner and related laboratory experimental paradigms (e.g., Buss, 1963) — happen to be those that are most likely to elicit greater aggression in men than women and greater aggression toward men than women. These paradigms manifest the four conditions associated with larger sex-of-subject and sex-of-target effect sizes: a 
laboratory setting, physical aggression, a semiprivate context, and required aggressive behavior. Given the positive value that the male gender role places on aggression, it is interesting to speculate on the possibility of bias on the part of researchers in their preference for a research paradigm that maximally elicits these sex differences. Perhaps researchers, especially if they are male, prefer to portray men as manifesting masculine qualities such as aggressiveness. Yet a prediction consistent with the hypothesis of such a bias-namely, that male authors should obtain larger sex-of-subject differences in the male direction than would female authors-was not substantiated. The absence of sex-of-author effects in our study as well as in Eagly and Crowley's (1986) and Hall's (1984) meta-analyses raises questions about the generality of Eagly and Carli's (1981) finding that male investigators tend to obtain and/or report different sexdifference findings than female investigators.

The sex differences obtained in laboratory aggression experiments probably had little direct bearing on the preferences for research methods used to study adult aggression. Instead, to understand why social psychologists have favored the teacherlearner and other laboratory-experimental paradigms for studying aggression, one might first acknowledge that investigators were primarily interested in physical aggression. Such a focus constrained them to a paradigm that elicited apparently severe physical aggression without causing physical harm. Probably few alternative paradigms could meet these requirements.

More broadly, the methods typically used by social psychologists to study aggression should be viewed in the context of the experimental paradigm (see Rosnow, 1981), which was dominant in social psychology during the period when most aggression research was carried out. Practitioners of experimental social psychology strongly preferred true experiments involving manipulation of independent variables and random assignment of subjects to conditions, features that characterize most of the studies included in this meta-analysis. This perceived necessity to conduct true experiments restricted many researchers to studying aggression in the context of short-term encounters with strangers. With the exception of the field experiments on aggression (e.g., Doob \& Gross, 1968; Harris, 1974), many of these experiments were relatively deficient in ecological validity.

To investigate aggression with more naturalistic methods and in social contexts other than brief encounters with strangers, researchers would have to turn to methods that are somewhat suspect in the experimental tradition-methods involving, for example, analyzing subjective reports of one's own and others' aggressiveness. Social psychologists' prejudice against such alternative methods in favor of true experiments using behavioral dependent variables reflects scientific activity that might be labeled agentic (Bakan, 1966), because of its controlling and objectifying qualities. Feminist scholars, including Carlson (1972), Wallston (1981), and Keller (1985), have described this agentic tendency and have argued that it is inherent in scientists' placement of natural phenomena at a distance and treatment of them as objects to be manipulated and controlled. Indeed, Macaulay (1985) has analyzed the importance of this theme for social psychological research on aggression.

Finally, we note that the current understanding of sex differences in aggressive behavior is somewhat limited. The variabil- ity we found in the magnitude of aggression sex differences is challenging, especially in view of the partial success of our social psychological predictors in accounting for this variability. Perhaps a framework incorporating additional predictors will account for more variability. If we are correct that adult social roles have the important function of channeling and regulating aggression so that it is expressed in socially approved ways, future research could well investigate in more detail the differing normative environments that surround women's and men's aggressive behavior.

\section{References}

Arkin, W., \& Dobrofsky, L. R. (1978). Military socialization and masculinity. Journal of Social Issues, 34(1), 151-168.

Bakan, D. (1966). The duality of human existence: An essay on psychology and religion. Chicago: Rand McNally.

Baron, R. A. (1977). Human aggression. New York: Plenum Press.

Baron, R. A., \& Eggleston, R. J. (1972). Performance on the "aggression machine": Motivation to help or harm? Psychonomic Science, 26, 321-322.

Berkowitz, L. (1964). Aggressive cues in aggressive behavior and hostility catharsis. Psychological Review, 71, 104-122.

Berkowitz, L., \& Donnerstein, E. I. (1982). External validity is more than skin deep: Some answers to criticisms of laboratory experiments. American Psychologist, 37, 245-257.

Bertilson, H. S. (1983). Methodology in the study of aggression. In R. G. Geen \& E. 1. Donnerstein (Eds.), Aggression: Theoretical and empirical reviews (Vol. 1, pp. 213-245). New York: Academic Press.

Bleier, R. (1984). Science and gender: A critique of biology and its theories on women. New York: Pergamon Press.

Bloom, L. Z., Coburn, K., \& Pearlman, J. (1975). The new assertive woman. New York: Delacourt.

Bowker, L. H. (1978). Women, crime, and the criminal justice system. Lexington, MA: Lexington Books.

Breines, W., \& Gordon, L. (1983). The new scholarship on family violence. Signs: Journal of Women in Culture and Society, 8, 490-531.

Broverman, I. K., Vogel, S. R., Broverman, D. M., Clarkson, F. E. \& Rosenkrantz, P. S. (1972). Sex-role stereotypes: A current appraisal. Journal of Social Issues, 28(2), 59-78.

Buss, A. H. (1961). The psychology of aggression. New York: Wiley.

Buss, A. H. (1963). Physical aggression in relation to different frustrations. Journal of Abnormal and Social Psychology, 67, 1-7.

Carlson, R. (1972). Understanding women: Implications for personality theory and research. Journal of Social Issues, 28(2), 17-32.

Carver, C. S. (1974). Facilitation of physical aggression through objective self-awareness. Journal of Experimental Social Psychology, 10, 365-370.

Carver, C. S. (1975). Physical aggression as a function of objective selfawareness and attitudes toward punishment. Journal of Experimental Social Psychology, 11, 510-519.

Cicone, M. V., \& Ruble, D. N. (1978). Beliefs about males. Journal of Social Issues, 34(1), 5-16.

Cohen, J., \& Cohen, H. (1983). Applied multiple regression/correlation analysis for the behavioral sciences (2nd ed.). Hillsdale, NJ: Erlbaum.

Doob, A. N., \& Gross, A. E. (1968). Status of frustrator as an inhibitor of horn-honking responses. Journal of Social Psychology, 76, 213218.

Eagly, A. H. (1983). Gender and social influence: A social psychological analysis. American Psychologist, 38, 971-981.

Eagly, A. H. (1986). Some meta-analytic approaches to examining the validity of gender-difference research. In J. S. Hyde \& M. C. Linn (Eds.), The psychology of gender: Advances through meta-analysis (pp. 159-177). Baltimore, MD: Johns Hopkins University Press. 
Eagly, A. H. (in press). Sex differences in social behavior: A social-role interpretation. Hillsdale, $\mathrm{NJ}$ : Erlbaum.

Eagly, A. H., \& Carli, L. L. (1981). Sex of researchers and sex-typed communications as determinants of sex differences in influenceability: A meta-analysis of social influence studies. Psychological Bulletin, 90, 1-20.

Eagly, A. H., \& Crowley, M. (1986). Gender and helping behavior: A meta-analytic review of the social psychological literature. Psychological Bulletin, 100, 283-308.

Eisenberg, N., \& Lennon, R. (1983). Sex differences in empathy and related capacities. Psychological Bulletin, 94, 100-131.

Fasteau, M. F. (1974). The male machine. New York: McGraw-Hill.

Feather, N. T. (Ed.). (1982). Expectations and actions: Expectancy-value models in psychology. Hillsdale, NJ: Erlbaum.

Fensterheim, H., \& Baer, J. (1975). Don't say yes when you want to say no: How assertiveness training can change your life. New York: McKay.

Feshbach, N. D. (1982). Sex differences in empathy and social behavior in children. In N. Eisenberg (Ed.), The development of prosocial behavior (pp. 315-338). New York: Academic Press.

Feshbach, S. (1955). The drive-reducing function of fantasy behavior. Journal of Abnormal and Social Psychology, 50, 3-11.

Fishbein, M., \& Ajzen, I. (1975). Belief, attitude, intention, and behavior: An introduction to theory and research. Reading, MA: AddisonWesley.

Frodi, A., Macauley, J., \& Thome, P. R, (1977). Are women always less aggressive than men? A review of the experimental literature. Psychological Bulletin, 84, 634-660.

Frost, W. D., \& Averill, J. R. (1982). Differences between men and women in the everyday experience of anger. In J. R. Averill, Anger and aggression: An essay on emotion (pp. 281-316). New York: SpringerVerlag.

Geen, R. G. (1976). The study of aggression. In R. G. Geen \& E. C. O'Neal (Eds.), Perspectives on aggression (pp. 1-9). New York: Academic Press.

Ghiselli, E. E. (1964). Theory of psychological measurement. New York: MoGraw-Hill.

Glass, G. V., McGaw, B., \& Smith, M. L. (1981). Meta-analysis in social research. Beverly Hills, CA: Sage.

Greenwald, A. G. (1975). Consequences of prejudice against the null hypothesis. Psychological Bulletin, 82, 1-20.

Hall, J. A. (1984). Nonverbal sex differences: Communication accuracy and expressive style. Baltimore, MD: Johns Hopkins University Press.

Hall, J. A., \& Halberstadt, A. G. (1986). Smiling and gazing. In J. S. Hyde \& M. C. Linn (Eds.), The psychology of gender: Advances through meta-analysis (pp. 136-158). Baltimore, MD: Johns Hopkins University Press.

Hamburg, D. A., \& Trudeau, M. B. (Eds.). (1981). Biobehavioral aspects of aggression. New York: Liss.

Harris, M. B. (1974). Mediators between frustration and aggression in a field experiment. Journal of Experimental Social Psychology, 10, 561-571.

Harvard University Computation Laboratory. (1955). Annals of the Computation Laboratory of Harvard University: Vol. 35. Tables of the cumulative binomial probability distribution. Cambridge, MA: Harvard University Press.

Hedges, L. V. (1981). Distribution theory for Glass's estimator of effect size and related estimators. Journal of Educational Statistics, 6, 107128.

Hedges, L. V. (1982a). Fitting categorical models to effect sizes from a series of experiments. Journal of Educational Statistics, 7, 119-137.

Hedges, L. V. (1982b). Fitting continuous models to effect size data. Journal of Educational Statistics, 7, 245-270.
Hedges, L. V., \& Becker, B. J. (1986). Statistical methods in the metaanalysis of research on gender differences. In J. S. Hyde \& M. C. Linn (Eds.), The psychology of gender: Advances through meta-analysis (pp. 14-50). Baltimore, MD: Johns Hopkins University Press.

Hedges, L. V., \& Olkin, I. (1985). Statistical methods for meta-analysis. Orlando, FL: Academic Press.

Hoffman, M. L. (1977). Sex differences in empathy and related behaviors. Psychological Bulletin, 84, 712-722.

Hoppe, C. M. (1979). Interpersonal aggression as a function of subject's sex, subject's sex role identification, opponent's sex, and degree of provocation. Journal of Personality, 47, 317-329.

Hyde, J. S. (1984). How large are gender differences in aggression? A developmental meta-analysis. Developmental Psychology, 20, 722736.

Hyde, J. S. (1986). Gender differences in aggression. In J. S. Hyde \& M. C. Linn(Eds.), The psychology of gender: Advances through metaanalysis (pp. 51-66). Baltimore, MD: Johns Hopkins University Press.

Keller, E. F. (1985). Reflections on gender and science. New Haven, CT: Yale University Press.

Knott, P. D., \& Drost, B. A. (1970). Sex-role identification, interpersonal aggression, and anger. Psychological Reports, 27, 154.

Krebs, D. L., \& Miller, D. T. (1985). Altruism and aggression. In G. Lindzey \& E. Aronson (Eds.), Handbook of social psychology (3rd ed., Vol. 2, pp. 1-71). New York: Random House.

Lando, H. A., Johnson-Payne, E., Gilbert, L. A., \& Deutsch, C. J. (1977). Sex differences in response to physical and nonphysical instigators. Sex Roles, 3, 523-535.

Lane, D. M., \& Dunlap, W. P. (1978). Estimating effect size: Bias resulting from the significance criterion in editorial decisions. British Journal of Mathematical and Statistical Psychology, 31, 107-112.

Leventhal, D. B., \& Shemberg, K. M. (1969). Sex role adjustment and nonsanctioned aggression. Journal of Experimental Research in Personality, 3, 283-286.

Leventhal, D. B., Shemberg, K. M., \& Van Schoelandt, S. K. (1968). Effects of sex-role adjustment upon the expression of aggression. Journal of Personality and Social Psychology, 8, 393-396.

Light, R. J., \& Pillemer, D. B. (1984). Summing up: The science of reviewing research. Cambridge, MA: Harvard University Press.

Lubek, 1. (1979). A brief social psychological analysis of research on aggression in social psychology. In A. R. Buss (Ed.), Psychology in social context (pp. 259-306). New York: Irvington.

Macaulay, J. (1985). Adding gender to aggression research: Incremental or revolutionary change? In V. E. O'Leary, R. K. Unger, \& B. S. Wallston (Eds.), Women, gender, and social psychology (pp. 191-224). Hillsdale, NJ: Erlbaum.

Maccoby, E. E., \& Jacklin, C. N. (1974). The psychology of sex differences. Stanford, CA: Stanford University Press.

Maccoby, E. E., \& Jacklin, C. N. (1980). Sex differences in aggression: A rejoinder and reprise. Child Development, 51, 964-980.

McClelland, D. C. (1961). The achieving society. New York: Van Nostrand.

McGuire, W. J. (1983). A contextualist theory of knowledge: Its implications for innovation and reform in psychological research. In $\mathbf{L}$. Berkowitz (Ed.), Advances in experimental social psychology (Vol. 16, pp. 1-47). Orlando, FL: Academic Press.

Parke, R. D., \& Slaby, R. G. (1983). The development of aggression. In P. H. Mussen (Ed.), Handbook of child psychology (Vol. 4, pp. 547641). New York: Wiley.

Pentz, M. W. (1980). Assertion training and trainer effects on unassertive and aggressive adolescents. Journal of Counseling Psychology, 27, 76-83.

Peplau, L. A. (1983). Roles and gender. In H. H. Kelley, E. Berscheid, A. Christensen, J. H. Harvey, T. L. Huston, G. Levinger, E. McClin- 
tock, L. A. Peplau, \& D. R. Peterson (Eds.), Close relationships (pp. 220-264). New York: Freeman.

Pleck, J. H. (1981). The myth of masculinity. Cambridge, MA: MIT Press.

Rajecki, D. W. (1983). Animal aggression: Implications for human aggression. In R. G. Geen \& E. I. Donnerstein (Eds.), Aggression: Theoretical and empirical reviews (Vol. 1, pp. 189-211). New York: Academic Press.

Richardson, D. C., Bernstein, S., \& Taylor, S. P. (1979). The effect of situational contingencies on female retaliative behavior. Journal of Personality and Social Psychology, 37, 2044-2048.

Robertson, W. H. (1960). Tables of the binomial distribution function for small values of $p$ (Scandia Corporation Monograph No. SCR143). Washington, DC: Office of Technical Services, U.S. Department of Commerce.

Rohner, R. P. (1976). Sex differences in aggression: Phylogenetic and enculturation perspectives. Ethos, 4, 57-72.

Rosenthal, R. (1978). Combining results of independent studies. Psychological Bulletin, 85, 185-193.

Rosenthal, R. (1984). Meta-analytic procedures for social research. Beverly Hills, CA: Sage.

Rosnow, R. L. (1981). Paradigms in transition: The methodology of social inquiry. New York: Oxford University Press.

Rothaus, P., \& Worchel, P. (1964). Ego support, communication, catharsis, and hostility. Journal of Personality, 32, 296-312.

Ruble, T. L. (1983). Sex stereotypes: Issues of change in the 1970s. Sex Roles, 9, 397-402.

Schuck, J., \& Pisor, K. (1974). Evaluating an aggression experiment by the use of simulating subjects. Journal of Personality and Social Psychology, 29, 181-186.

Shapiro, S. S., \& Wilk, M. B. (1965). An analysis of variance test for normality (complete samples). Biometrika, 52, 591-611.

Shemberg, K. M., Leventhal, D. B., \& Allman, L. (1968). Aggression machine performance and rated aggression. Journal of Experimental Research in Personality, 3, 117-119.

Simmel, E. C., Hahn, M. E., \& Walters, J. K. (Eds.). (1983). Aggressive behavior: Genetic and neural approaches. Hillsdale, NJ: Erlbaum.
Smith, T. W. (1984). The polls: Gender and attitudes toward violence. Public Opinion Quarterly, 48, 384-396.

Spence, J. T., \& Helmreich, R. L. (1978). Masculinity \& femininity: Their psychological dimensions, correlates, \& antecedents. Austin: University of Texas Press.

Stein, P. J., \& Hoffman, S. (1978). Sports and male role strain. Journal of Social Issues, 34(1), 136-150.

Straus, M. A. (1980). Victims and aggressors in marital violence. American Behavioral Scientist, 23, 681-704.

Straus, M. A., Gelles, R. J., \& Steinmetz, S. K. (1980). Behind closed doors: Violence in the American family. Garden City, NY: Anchor Books.

Tedeschi, J. T. (1983). Social influence theory and aggression. In R. G. Geen \& E. I. Donnerstein (Eds.), Aggression: Theoretical and empirical reviews (Vol. 1, pp. 135-162). New York: Academic Press.

Tedeschi, J. T., Smith, R. B., III, \& Brown, R. C., Jr. (1974). A reinterpretation of research on aggression. Psychological Bulletin, 81, 540562.

Titley, R. W., \& Viney, W. (1969). Expression of aggression toward the physically handicapped. Perceptual \& Motor Skills, 29, 51-56.

U.S. Department of Justice. Office of Justice Assistance, Research, and Statistics. (1979). How to protect yourself against sexual assault: Take a bite out of crime. Washington, DC: U.S. Government Printing Office.

U.S. Department of Labor. Bureau of Labor Statistics. (1980). Perspectives on working women: A databook (Bull. No. 2080). Washington, DC: U.S. Government Printing Office.

Wallston, B. S. (1981). What are the questions in psychology of women? A feminist approach to research. Psychology of Women Quarterly, 5, 597-617.

White, J. W. (1983). Sex and gender issues in aggression research. In R. G. Geen \& E. I. Donnerstein (Eds.), Aggression: Theoretical and empirical reviews (Vol. 2, pp. 1-26). New York: Academic Press.

Whyte, W. H., Jr. (1956). The organization man. New York: Simon \& Schuster. 


\section{Appendix}

\section{Studies Used in the Meta-Analysis 9}

Ahmed, S. M. S. (1982). Factors affecting frustrating and aggression relationships. Journal of Social Psychology, 116, 173-177. (32)

Arenson, S. J. (1977). Reactions to invasions of marked seats at a racetrack. Social Behavior and Personality, 5, 225-228.

Atkinson, C., \& Polivy, J. (1976). Effects of delay, attack, and retaliation on state depression and hostility. Journal of Abnormal Psychology, 85, 570-576. (49)

Baron, R. A., \& Ball, R. L. (1974). The aggression-inhibiting influence of nonhostile humor. Journal of Experimental Social Psychology, 10, 23-33.

Berkowitz, L. (1960). Repeated frustrations and expectations in hostility arousal. Journal of Abnormal and Social Psychology, 60, 422-429.

Berkowitz, L., \& Holmes, D. S. (1959). The generalization of hostility to disliked objects. Journal of Personality, 27, 565-577.

Berkowitz, L., \& Rawlings, E. (1963). Effects of film violence on inhibitions against subsequent aggression. Journal of Abnormal and Social Psychology, 66, 405-412.

Bond, M. H., \& Dutton, D. G. (1975). The effect of interaction anticipation and experience as a victim on aggressive behavior. Journal of Personality, 43, 515-527.

Buss, A. H. (1963). Physical aggression in relation to different frustrations. Journal of Abnormal and Social Psychology, 67, 1-7. (22)

Buss, A. H. (1966a). The effect of harm on subsequent aggression. Journal of Experimental Research in Personality, 1, 249-255.

Buss, A. H. (1966b). Instrumentality of aggression, feedback, and frustration as determinants of physical aggression. Journal of Personality and Social Psychology, 3, 153-162. (26)

Buvinic, M. L. (1975). Sex differences in the aggressive consequences of expressing feelings or opinions. Dissertation Abstracts International. 36, 1498B. (University Microfilms No. 75-12, 890) (25)

Chase, L. J., \& Mills, N. H. (1973). Status of frustrator as facilitator of aggression: A brief note. Journal of Psychology, 84, 225-226. (36)

Deaux, K. K. (1971). Honking at the intersection: A replication and extension. Journal of Social Psychology, 84, 159-160. (31)

Doob, A. N., \& Gross, A. E. (1968). Status of frustrator as an inhibitor of horn-honking responses. Journal of Social Psychology, 76, 213218. (20)

Edwards, N. L. (1968). Aggressive expression under threat of retaliation. Dissertation Abstracts International, $28,3470 \mathrm{~B}$. (University Microfilms No. 68-00, 922) $(10,35)$

Epstein, R. (1965). Authoritarianism, displaced aggression, and social status of the target. Journal of Personality and Social Psychology, 2, 585-589. (9)

Feshbach, S. (1955). The drive-reducing function of fantasy behavior. Journal of Abnormal and Social Psychology, 50, 3-11.

Fischer, D. G., Kelm, H., \& Rose, A. (1969). Knives as aggression-eliciting stimuli. Psychological Reports, 24, 755-760. (33)

Fisher, J. L., \& Harris, M. B. (1976). Modeling, arousal, and aggression. Journal of Social Psychology, 100, 219-226. (42)

Frodi, A. (1978). Experiential and physiological responses associated with anger and aggression in women and men. Journal of Research in Personality, 12, 335-349. (13)

Gaebelein, J. W. (1977). Sex differences in instigative aggression. Journal of Research in Personality, 11, 466-474. (24)

Gentry, W. D. (1972). Biracial aggression: I. Effect of verbal attack and sex of victim. Journal of Social Psychology, 88, 75-82.

Golin, S., \& Romanowski, M. A. (1977). Verbal aggression as a function of sex of subject and sex of target. Journal of Psychology, 97, 141150.

Goodwin, A. R. (1973). The effects of locus of control and feedback cues on behavioral aggression. Dissertation Abstracts International, 34, 2387A. (University Microfilms No. 73-27, 298).

Harris, M. B. (1973). Field studies of modeled aggression. Journal of Social Psychology, 89, 131-139. (12)

Harris, M. B. (1974a). Aggressive reactions to a frustrating phone call. Journal of Social Psychology, 92, 193-198.

Harris, M. B. (1974b). Mediators between frustration and aggression in a field experiment. Journal of Experimental Social Psychology, 10, 561-571. $(45,48)$

Harris, M. B. (1976). Instigators and inhibitors of aggression in a field experiment. Journal of Social Psychology, 98, 27-38. $(39,40)$

Harris, M. B., \& Huang, L. C. (1974). Aggression and the attribution process. Journal of Social Psychology, 92, 209-216.

Harris, M. B., \& Klingbeil, D. R. (1976). The effects of ethnicity of subject and accent and dependency of confederate on aggressiveness and altruism. Journal of Social Psychology, 98, 47-53.

Harris, M. B., Liguori, R., \& Joniak, A. (1973). Aggression, altruism, and models. Journal of Social Psychology, 91, 343-344.

Harris, M. B., \& Samerotte, G. (1975). The effects of aggressive and altruistic modeling on subsequent behavior. Journal of Social Psychology, 95, 173-182. $(7,17)$

Hedrick, T. E. (1977). Behavioral and autonomic responses to aggression by traditional and nontraditional men and women. Dissertation Abstracts International, 37, 4755B. (University Microfilms No. 77$05,610)(16,34)$

Hynan, M. T. (1982). Aggression in a competitive task. Psychological Reports, 50, 663-672. (21)

Hynan, M. T., \& Esselman, J. A. (1981). Victims and aggression. Bulletin of the Psychonomic Society, 18, 169-172. (4)

Hynan, M., Harper, S., Wood, C., \& Kallas, C. (1980). Parametric effects of blocking and winning in a competition paradigm of human aggression. Bulletin of the Psychonomic Society, 16, 295-298. (23, 37)

Jaffe, Y., Malamuth, N., Feingold, J., \& Feshbach, S. (1974). Sexual arousal and behavioral aggression. Journal of Personality and Social Psychology, 30, 759-764. (15)

Juhnke, R., Goldman, M., \& Baer, R. (1977). Predispositional frustration responses and the expression of evaluations. Journal of Social Psychology, 102, 275-282.

Koerner, F. E. (1977). The effects of depression and sex on aggressive affect and behavior toward the self and toward others. Dissertation Abstracts International, 38, 1887B-1888B. (University Microfilms No. $77-22,025)(41,46)$

Konečni, V. J. (1975). The mediation of aggressive behavior: Arousal level versus anger and cognitive labeling. Journal of Personality and Social Psychology, 32, 706-712. (19)

Lando, H. A., \& Donnerstein, E. l. (1978). The effects of a model's success or failure on subsequent aggressive behavior. Journal of Research in Personality, 12, 225-234. (6)

Lando, H. A., Johnson-Payne, E., Gilbert, L. A., \& Deutsch, C. J. (1977). Sex differences in response to physical and nonphysical instigators. Sex Roles, 3, 523-535. (14, 47)

Larsen, K. S., Coleman, D., Forbes, J., \& Johnson, R. (1972). Is the subject's personality or the experimental situation a better predictor of a subject's willingness to administer shock to a victim? Journal of Personality and Social Psychology, 22, 287-295. (38, 43, 44)

\footnotetext{
${ }^{9}$ Sequence numbers of studies appearing in Table 3 are given in parentheses after each reference. If no number is given, it was not possible to calculate a sex-of-subject effect size from the findings in the article.
} 
Leak, G. K. (1974). Effects of hostility arousal and aggressive humor on catharsis and humor preference. Journal of Personality and Social Psychology, 30, 736-740.

Mueller, C., \& Donnerstein, E. I. (1977). The effects of humor-induced arousal upon aggressive behavior. Journal of Research in Personality, $11,73-82$.

Raden, D. (1974). The relationship between prejudice and overt hostile behavior. Dissertation Abstracts International, 34, 6747B-6748B. (University Microfilms No. 74-00, 494) (3)

Rogers, R. W. (1980). Expressions of aggression: Aggression-inhibiting effects of anonymity to authority and threatened retaliation. Personality and Social Psychology Bulletin, 6, 315-320. (11)

Scharff, W. H., \& Schlottmann, R. S. (1973). The effects of verbal reports of violence on aggression. Journal of Psychology, 84, 283-290. $(28,29)$

Scheier, M. F., Buss, A. H., \& Buss, D. M. (1978). Self-consciousness, self-report of aggressiveness, and aggression. Journal of Research in Personality, 12, 133-140.

Schuck, S. Z., Schuck, A., Hallam, E., Mancini, F., \& Wells, R. (1971). Sex differences in aggressive behavior subsequent to listening to a radio broadcast of violence. Psychological Reports, 28, 931-936. (2)

Siegman, A. W., \& Dintzer, L. (1977). The catharsis of aggression and hostility. Psychological Reports, 41, 399-410. (18)
Taylor, S. P., \& Epstein, S. (1967). Aggression as a function of the interaction of the sex of the aggressor and the sex of the victim. Journal of Personality, 35, 474-486. (30)

Titley, R. W., \& Viney, W. (1969). Expression of aggression toward the physically handicapped. Perceptual \& Motor Skills, 29, 51-56. (8)

Turner, C. W., Layton, J. F., \& Simons, L. S. (1975). Naturalistic studies of aggressive behavior: Aggressive stimuli, victim visibility, and horn honking. Journal of Personality and Social Psychology, 31, 10981107. (50)

Unger, R. K., Raymond, B. J., \& Levine, S. M. (1974). Are women a "minority" group? Sometimes! International Journal of Group Tensions, 4, 71-81. (5)

Yinon, Y. M., Jaffe, Y. M., \& Feshbach, S. (1975). Risky aggression in individuals and groups. Journal of Personality and Social Psychology, 31, 808-815. (1)

Youssef, Z. I. (1968). The role of race, sex, hostility, and verbal stimulus in inflicting punishment. Psychonomic Science, 12, 285-286. (27)

Received August 5, 1985

Revision received February 13, 1986

\section{Psychological Documents to Resume Operation}

On June 16, 1986, the on-demand publication system Psychological Documents, published by the American Psychological Association from 1971 through 1985, was sold to Select Press. Select Press will begin publishing new volumes this year and, as of June 16, 1986, began fulfilling orders for documents accepted into the system while it was published by APA.

Peer-reviewed documents were published by APA under the experimental system (formerly Journal Supplement Abstract Service) for 15 years. A catalog containing synopses of each document accepted into the system was published on a subscription basis. Those wishing to have a copy of the full-text of a document could order a copy in either microfiche or paper.

During periodic evaluation of the service, however, APA found that as a result of low volume, the difficulties of providing service within existing systems, the expenses related to fulfilling orders, and the cost of maintaining an editorial office, it was extremely difficult for APA to maintain service that was both timely and economical. After an extensive review of the history of the system and intensive evaluation of the expenses related to it, the APA Council of Representatives voted in 1985 to discontinue publication of Psychological Documents with publication of the December 1985 catalog. APA was to continue to fulfill orders for individual copies of documents until December 1986, assuming that no alternative publisher could be found. Possible alternative publishers included APA divisions, individuals, and commercial publishers. In mid-1985, Select Press approached APA and negotiations were begun.

Select Press will continue to operate the system as a peer-reviewed "journal" or document service. It will continue to feature specialized documents suitable for individual circulation such as technical reports, annotated and technical bibliographies, original data sets, test instruments, test manuals, and papers that would ordinarily be too long to be considered for regular journals. Select Press expects to expand the system to cover a broader range of documents including interdisciplinary content and possibly brief, early announcements of new findings. Select Press also publishes the interdisciplinary Journal of Social Behavior and Personality. Further information about Psychological Documents may be obtained from Select Press at P.O. Box 9838, San Rafael, CA 94912. 